Portland State University

PDXScholar

Spring 1-1-2012

\title{
Climate Change Effects and Water Vulnerability in the Molalla Pudding River Basin, Oregon, USA
}

Susan Amelia Wherry

Portland State University

Follow this and additional works at: https://pdxscholar.library.pdx.edu/open_access_etds

Part of the Climate Commons, and the Water Resource Management Commons Let us know how access to this document benefits you.

\section{Recommended Citation}

Wherry, Susan Amelia, "Climate Change Effects and Water Vulnerability in the Molalla Pudding River Basin, Oregon, USA" (2012). Dissertations and Theses. Paper 556.

https://doi.org/10.15760/etd.556

This Thesis is brought to you for free and open access. It has been accepted for inclusion in Dissertations and Theses by an authorized administrator of PDXScholar. Please contact us if we can make this document more accessible: pdxscholar@pdx.edu. 
Climate Change Effects and Water Vulnerability in the Molalla Pudding River Basin, Oregon, USA

by

Susan Amelia Wherry

A thesis submitted in partial fulfillment of the requirements for the degree of

Master of Science

in

Civil and Environmental Engineering

Thesis Committee:

Hamid Moradkhani, Chair

David Jay

Alan Yeakley

Portland State University

(C)2012 


\begin{abstract}
Water management plans are typically developed using historical data records and historical return periods for extreme events, such as floods or droughts. Since these analyses of return periods typically assume a certain degree of stationarity (constant mean, standard deviation, distribution) in hydrologic variables, the potential future impacts of climate change are excluded. In developing water management plans, predicted changes to climate variables should be considered to evaluate the degree of non-stationarity that may exist in the future. In this way, regions most sensitive to climate change can be identified and managed appropriately.

This study performed such a task by using predicted climate data that were downscaled from general circulation models (GCM) by regional climate models (RCM) to compare climate variables in the historical period of 1971-1998 to the future period of 2041-2068. The study evaluated the precipitation and minimum/maximum temperature data from five different GCM/RCM combinations: 1) CCSM/CRCM; 2) CCSM/WRFG; 3) CGCM3/CRCM; 4) CGCM3/WRFG; and 5) HadCM3/HRM3. The five datasets were then used to calculate drought indices and drive a calibrated PRMS model of the Molalla Pudding river basin in order to evaluate changes in droughts and streamflow. The predicted changes in droughts and streamflow were then evaluated with social/economic factors for twelve cities in the Molalla Pudding river basin by two different water vulnerability indices. The index values were used to determine a rank for each city that indicated its relative vulnerability to water scarcity as compared to the other cities.

In this study, three out of the five datasets predicted increased precipitation (+97$115 \mathrm{~mm} /$ year) over the Molalla Pudding basin and the two datasets using the CCSM


GCM data predicted either no change or slightly decreased precipitation $(-60 \mathrm{~mm} / \mathrm{year})$ over the Molalla Pudding basin in 2041-2068. All datasets predicted increased minimum and maximum average temperature of $+1.5^{\circ} \mathrm{C}$ and $+1.4^{\circ} \mathrm{C}$ respectively, and all datasets displayed increasing trends in temperature. The drought indices predicted fewer drought events (-2.4 events) over 2041-2068 with no change in duration, and no change to the number of serious drought events over 2041-2068 but with increased durations $(+1.9$ months). Results from the hydrologic modeling predicted increased streamflow (+4-249 cfs) in four out of the five future datasets. Using the predicted changes in hydrologic variables and social/economic census data from 2000, two types of water vulnerability indices were calculated for the twelve cities of interest. The results suggested that cities in the western portion of the basin would be more susceptible to current and future water vulnerability due to high irrigation demands for water and high social vulnerability as determined by minority populations and higher poverty, while the small cities with less dependence on agriculture would be less vulnerable. 


\section{Dedication}

I humbly dedicate this thesis to my husband, Dominick Allen McIntosh, for his encouragement, support and friendship during my undergraduate and graduate programs. I would also like to dedicate this work to my mother, Ann Wherry, for always promoting education and life-long learning. 


\section{Acknowledgements}

First, I would like to acknowledge and thank my advisor, Dr. Hamid Moradkhani, for introducing me academically to hydrology and for encouraging me to approach and take on new approaches in hydrologic assessment and modeling. He has helped me find a career that I truly love, and for that I will be forever grateful.

I would also like to acknowledge my committee members and influential teachers, Dr. Alan Yeakley and Dr. David Jay. Their courses and teaching have broadened my understanding of science, hydrology, engineering and the crossovers between these three fields and I have been infected by their enthusiasm for earth sciences. 


\section{Table of Contents}

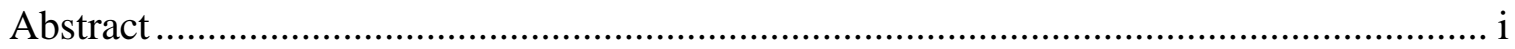

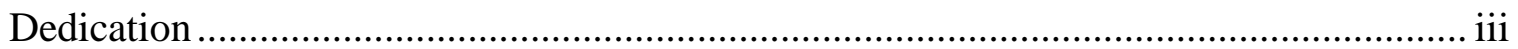

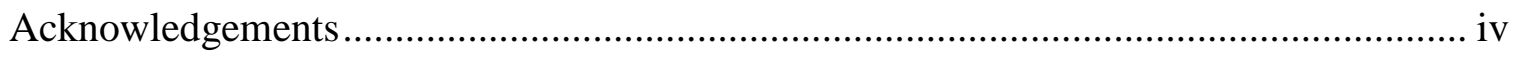

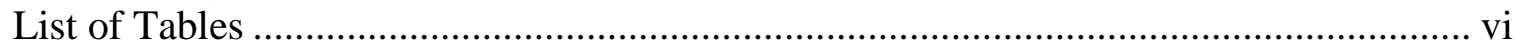

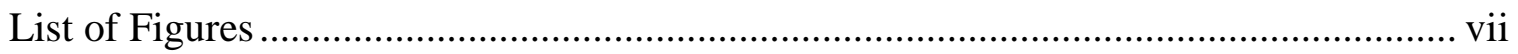

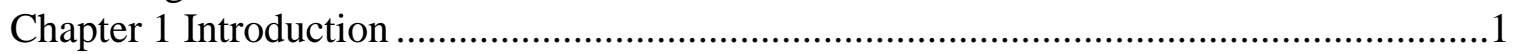

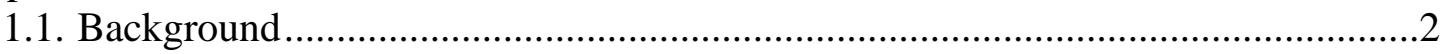

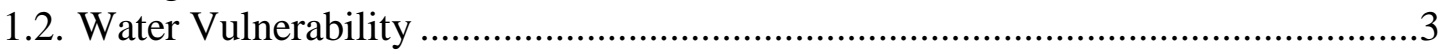

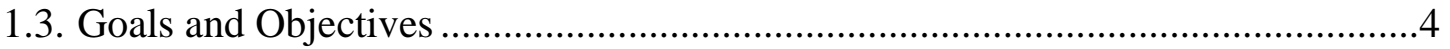

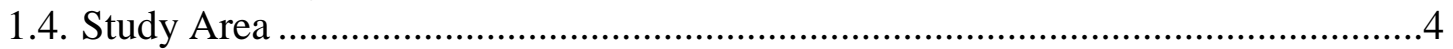

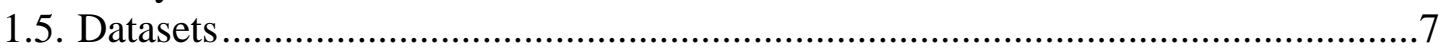

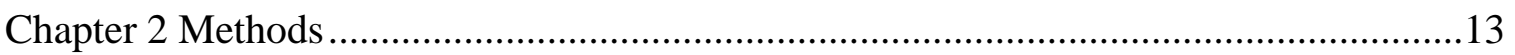

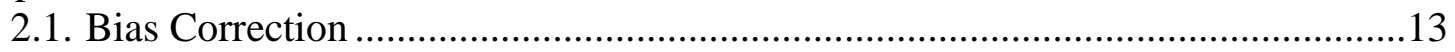

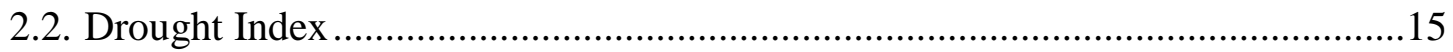

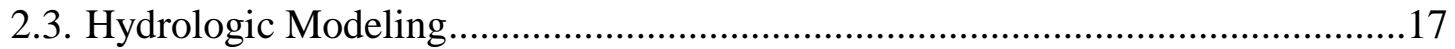

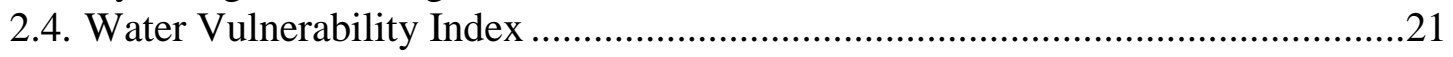

2.5. Social Vulnerability Index with Water Components.......................................23

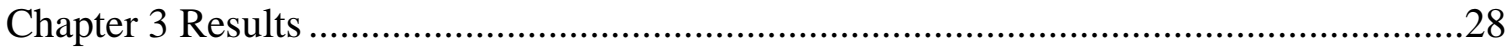

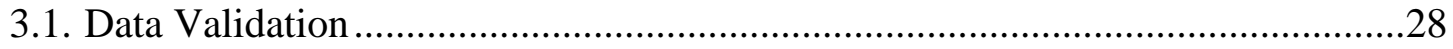

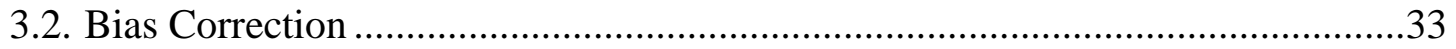

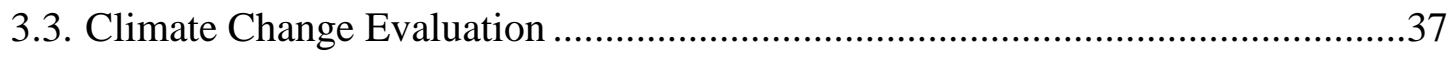

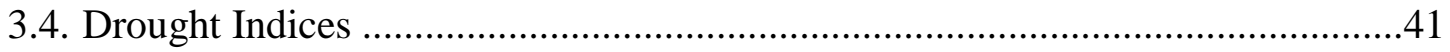

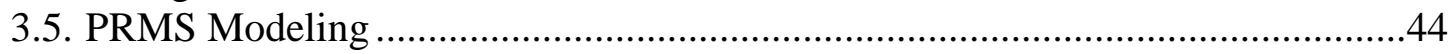

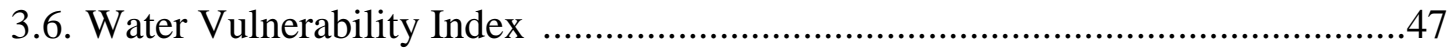

3.7. Social Vulnerability Index with Water Components .......................................50

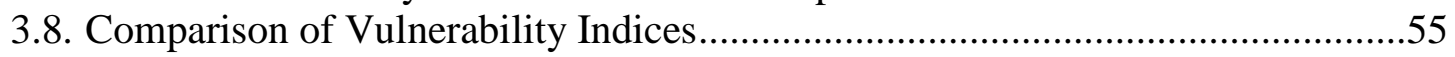

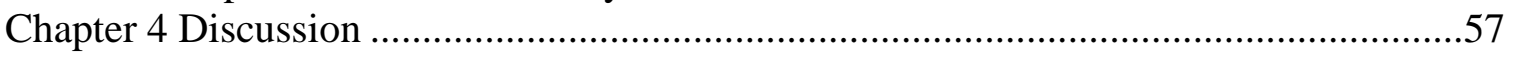

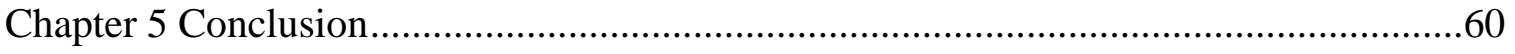

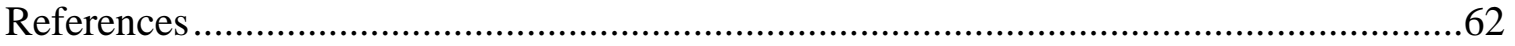




\section{List of Tables}

Table 1: Observed data gage elevations..................................................................

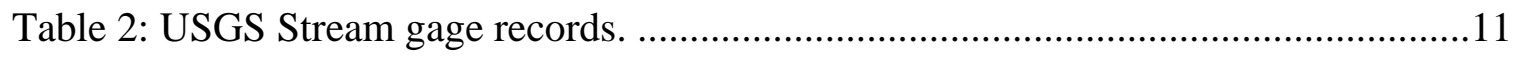

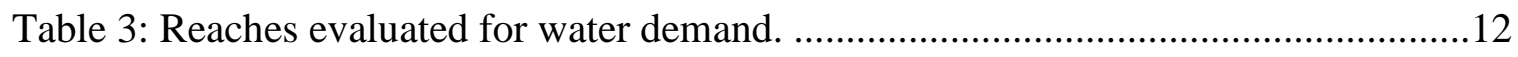

Table 4: Social vulnerability factors considered for the SOVI + WC . ...........................27

Table 5: Statistics to verify the accuracy of the Molalla Pudding PRMS calibration. ......44

Table 6: Principal components and associated vulnerability dimensions for the Molalla Pudding basin over the historical period.....................................................52

Table 7: Principal components and associated vulnerability dimensions for the Molalla Pudding basin over the future period. 


\section{List of Figures}

Figure 1: Position of the Molalla Pudding basin with respect to Willamette river basin in

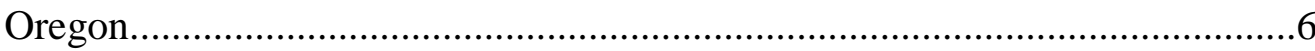

Figure 2: Protected ground and surface drinking water source areas. .............................

Figure 3: (Upper) Location of WRCC gages from which observed precipitation and temperature data were collected; (Lower) Location of grid points for the NARCCAP RCMs: WRFG, HRM3 and CRCM.........................................10

Figure 4: Schematic of the PRMS model water balance system. ...................................20

Figure 5: Precipitation distributions over 1971-1998 before bias correction. ...................30

Figure 6: Max temperature distributions over 1971-1998 before bias correction.............31

Figure 7: Min temperature distributions over 1971-1998 before bias correction..............32

Figure 8: Precipitation distributions over 1971-1998 after bias correction. ......................34

Figure 9: Max temperature distributions over 1971-1998 after bias correction. ...............35

Figure 10: Min temperature distributions over 1971-1998 after bias correction...............36

Figure 11: Precipitation distributions over 2041-2068 after bias correction. ....................38

Figure 12: Max temperature distributions over 2041-2068 after bias correction. .............39

Figure 13: Min temperature distributions over 2041-2068 after bias correction...............40

Figure 14: Change in the number of drought events from 1971-1998 to 2041-2068.......42

Figure 15: Change in the duration of serious events from 1971-1998 to 2041-2068.......42

Figure 16: Change in the intensity of drought events from 1971-1998 to 2041-2068. ....43

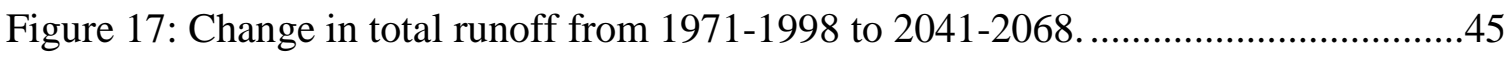

Figure 18: Change in future seasonal runoff ............................................................46

Figure 19: Historical period 1971-1998 WVI scores for Molalla Pudding basin cities.

Cities on the left are least vulnerable and cities on the right are most vulnerable.

Figure 20: Future period 2041-2068 WVI scores for Molalla Pudding basin cities. Cities on the left are least vulnerable and cities on the right are most vulnerable....49

Figure 21: Historical and future SOVI + Water Component scores for Molalla Pudding basin cities. Cities on the left are least vulnerable and cities on the right are most vulnerable................................................................................54

Figure 22: Comparison of WVI and SOVI + WC rankings for the historical period........56

Figure 23: Comparison of WVI and SOVI + WC rankings for the future period. ............56

Figure 24: Stream reaches (red) with existing Total Maximum Daily Load (TMDL) requirements for various water quality and habitat vulnerability variables.....59 


\section{Chapter 1 Introduction}

Water management is necessary for any community of water users. There exists a bare minimum of water necessary for life, and within a community all individuals become invested in water distribution. Water management plans are put into place to ensure that all represented members of a community have access to an appropriate amount of water for survival. While these plans are often designed to handle worst case scenarios, such as drought or contamination, a plan can never account for every outcome. Development of water management plans must rely on historical records in order to determine return periods for extreme events, however many tools to evaluate these types of events assume stationarity, and don't account for the possibility of changing means, standard deviations or distributions of variables like precipitation and streamflow. Should anthropogenic climate change result in non-stationary climate variables, which is often the prediction, existing water management plans would be insufficient to describe the true vulnerability.

In the Pacific Northwest, water resources seem plentiful due to the great amount of precipitation received in the region, however, with that water comes great political interest. Water rights are divided between citizens, agriculture and habitat, to name a few, and in times of drought and water stress, all groups tend to suffer. While the occurrence of droughts and low precipitation years cannot be prevented, water management plans can be developed in order to best allocate resources during times of stress. The first step in developing appropriate water management plans is to compare water vulnerability in regions of interest over time periods of interest. 


\subsection{Background}

The first step in performing a climate change study over a refined region of interest, like the Molalla Pudding basin, is to find appropriately scaled data. The primary source of anthropogenically influenced, future climate data come from atmospheric/oceanic coupled general circulation models (GCM) that have been driven for various climate change scenarios. GCMs are relatively coarse in resolution and therefore unable to resolve significant subgrid scale features including topography and land use as needed in hydrologic modeling and impact assessment. Therefore, some form of downscaling is needed to produce scenarios of higher spatial resolution than currently delivered by raw GCM output. Downscaling is the process of translating large scale atmospheric data, called predictors, to finer spatial resolution data, called predictands, to allow for the local analysis of climate change effects. By means of the future values of the GCM variables, downscaling methods can calculate the climatologic values of temperature and precipitation, which are then used to assess the hydrologic impacts due to the climate change.

Generally two types of downscaling approaches are employed, which are known as "dynamic" and "statistical" methods. The dynamic downscaling techniques are performed by nesting a physically based, small spatial resolution regional climate model within the grid of a GCM output. GCM outputs are used as boundary conditions to drive the regional model (Wood et al., 2004). The second method, statistical downscaling, is performed by deriving empirical mathematical relationships between GCM climate variables and regional scale variables (Wood et al., 2004). 
Downscaled climate data can be used to assess climate change impacts at the regional scale by comparing the statistics and trends of variables, like precipitation and temperature, over historical and future periods. By considering multiple GCM outputs, a degree of uncertainty for future climate projections can be developed. Downscaled climate data can also be used to drive calibrated hydrologic models in order to determine expected changes in streamflow and snowpack.

\subsection{Water Vulnerability}

For this study, the primary source of variability considered for future water resources is anthropogenic climate change. Climate change is evaluated specifically in the form of water supply, as defined by precipitation anomalies and streamflow. Since water vulnerability encompasses social/economic aspects of a community in addition to its hydrology, a number of social vulnerability factors were investigated as well. In this way social and hydrologic factors were assessed simultaneously to develop water vulnerability indices unique to the study region, the Molalla Pudding basin in Oregon. The water vulnerability indices are conceptual indices that allow the user to include appropriate variables that contribute to water scarcity at their own discretion. In this study specific social and hydrologic factors are presented, however the concept is adaptable. Additionally, the water vulnerability indices are calculated in such a way that risk is assessed in a relative sense as opposed to within a rigid, predefined/empirical framework. The water vulnerability indices determine a relative ranking system within a study region, which enables water management plans to identify, and target for improvement, high risk areas. 


\subsection{Goals and Objectives}

The first goal of the study is to evaluate the climate change impacts based on a high projected emissions scenario over the Molalla Pudding basin. Climate change will be evaluated by comparing the changes in mean, standard deviation, distribution, trend and seasonality of precipitation and temperature over the historical period, 1971-1998, and the future period, 2041-2068. Predicted climate data will then be used to run a hydrologic model and determine expected changes in various hydrologic variables.

The second goal of this study is to calculate water vulnerability indices that will rank the cities of the Molalla Pudding basin. The concept of water vulnerability encompasses hydrological, social and economic factors, so the index will be developed using a number of variables. Hydrological factors will include expected changes in quantity, groundwater supply and stream temperature. Social and economic factors will be determined from the year 2000 census data and will include the following measures of vulnerability: age, income/poverty, minority status, disability, employment, mobile homes/renters, gender, education and density.

\subsection{Study Area}

The study area chosen for analysis is the Molalla-Pudding basin in Northwest Oregon, which has a total area of $\sim 2,270 \mathrm{~km}^{2}$ and drains into the middle portion of the Willamette River. The basin was chosen for a number of reasons, including data availability, total maximum daily load (TMDL) concerns and land use composition. The Molalla Pudding basin was also chosen due to the regular occurrence of flooding in the Lower Pudding river, where significant agriculture needs exist. Understanding the 
vulnerabilities of a high agriculture basin are important because of the importance of food supply and expected yield. Should the risk of low agricultural yield be expected to increase for water supply reasons, the management of water resources should be reevaluated to ensure minimized changes in agriculture output.

The major rivers of the basin are the Molalla and Pudding rivers, flowing 40 and 39 kilometers respectively, and these rivers divide the basin into two distinct areas. The eastern portion of the basin containing the Molalla river, is characterized by a large area of high, forested land in the upper portion of the river reach, which drops to lower elevation agricultural and urban areas, while the western portion of the basin containing the Pudding river is predominantly characterized by agricultural use and some urban development. Both rivers transmit most of their flow (80-90\%) during the wet season of November-April, and are primarily precipitation driven as snowpack does not contribute greatly to annual discharge. The fluctuation in flow between winter and summer months is great, particularly in the Pudding river where more surface water is diverted for irrigation purposes. While the Pudding river has greater winter average flows $\left(\mathrm{Q}_{\text {avg,Molalla }}=2,392 \mathrm{cfs}\right.$ and $\left.\mathrm{Q}_{\mathrm{avg}, \text { Pudding }}=2,927 \mathrm{cfs}\right)$, the river then takes a much greater drop to lower summer average flows $\left(\mathrm{Q}_{\mathrm{avg}, \text { Molalla }}=100-200 \mathrm{cfs}\right.$ and $\left.\mathrm{Q}_{\mathrm{avg}, \text { Pudding }}=46 \mathrm{cfs}\right)$, most likely due to diversions. Current late summer in-stream water requirement for habitat and minimization of pollution in the Pudding river is approximately $12-40 \mathrm{cfs}$, which is already quite low and violated from time to time due to current management scenarios. Climate change analyses will help to determine if the frequency of violation will increase or decrease in future years. 


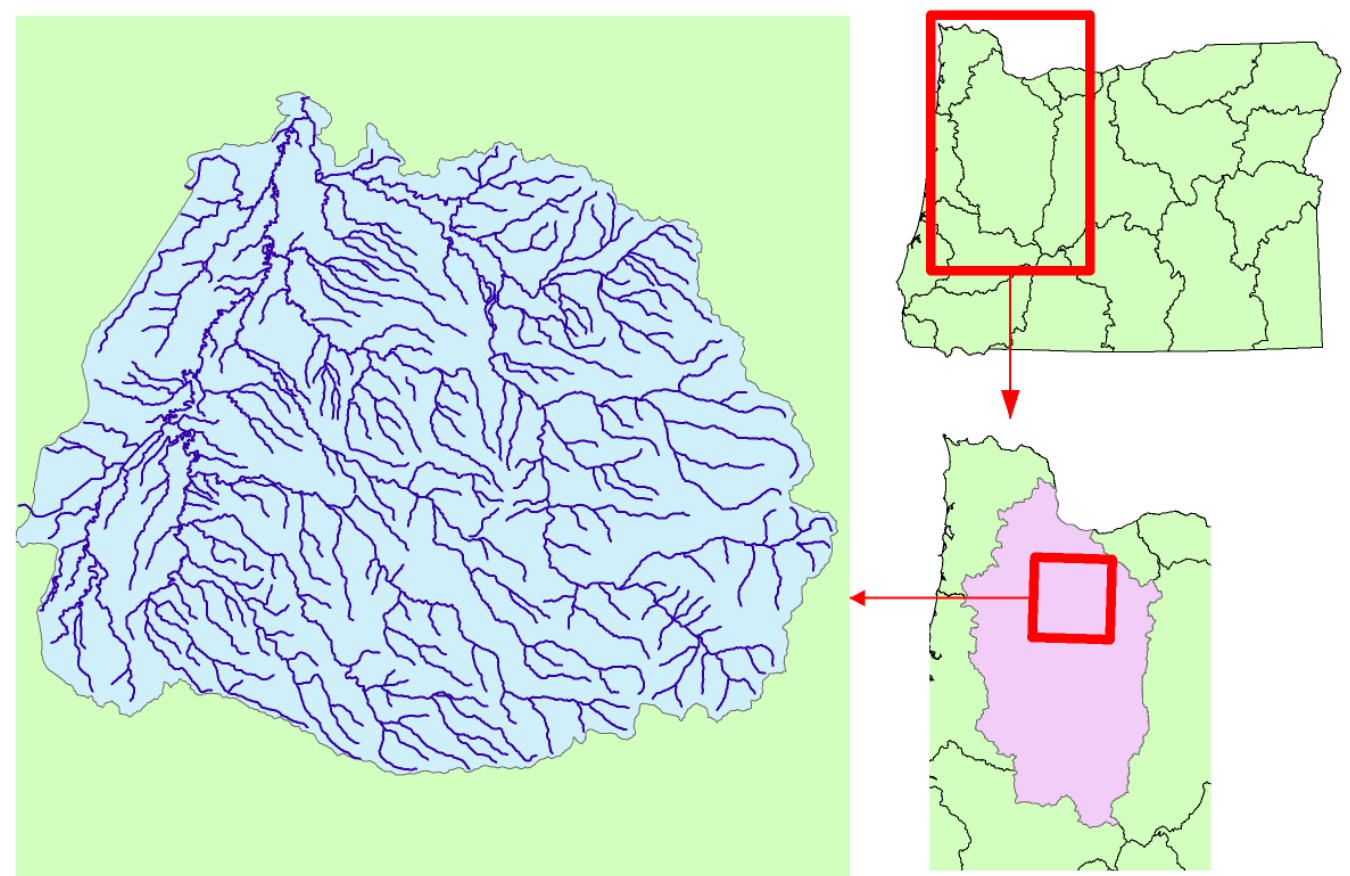

Figure 1: Position of the Molalla Pudding basin with respect to Willamette river basin in Oregon.

In addition to agriculture and habitat/pollution concerns, the Molalla and Pudding rivers (and their tributaries) provide drinking water for a number of the major cities in the basin. In the eastern portion of the basin, the Molalla river and its tributaries are protected surface water drinking sources for the cities of Canby, Molalla and Colton while in the western basin, Silver creek and Abiqua creek (tributaries of the Pudding river) are protected surface water drinking sources for the city of Silverton. In addition to surface water sources, a number of protected groundwater drinking source areas are scattered throughout the basin, primarily in the western portion. These protected groundwater drinking source areas service at least 24 schools (mostly elementary grades), 22 mobile home parks, various housing developments/businesses and cities including: Aurora, Barlow, Donald, Gervais, Hubbard, Keizer, Mount Angel, Mulino, Scotts Mills, Salem, Wilsonville and Woodburn. The protected groundwater drinking source areas 
drain to approximately 267 springs/wells and for roughly one third of these springs ( 93) the maximum water time of travel to the intake is less than 5 years. These springs will be more sensitive and respond quicker to future climate changes. The majority two thirds of total wells $(\sim 165)$ have a maximum water time of travel to the intake of 10-15 years and therefore water users will be impacted by climate changes much later than smaller spring users.

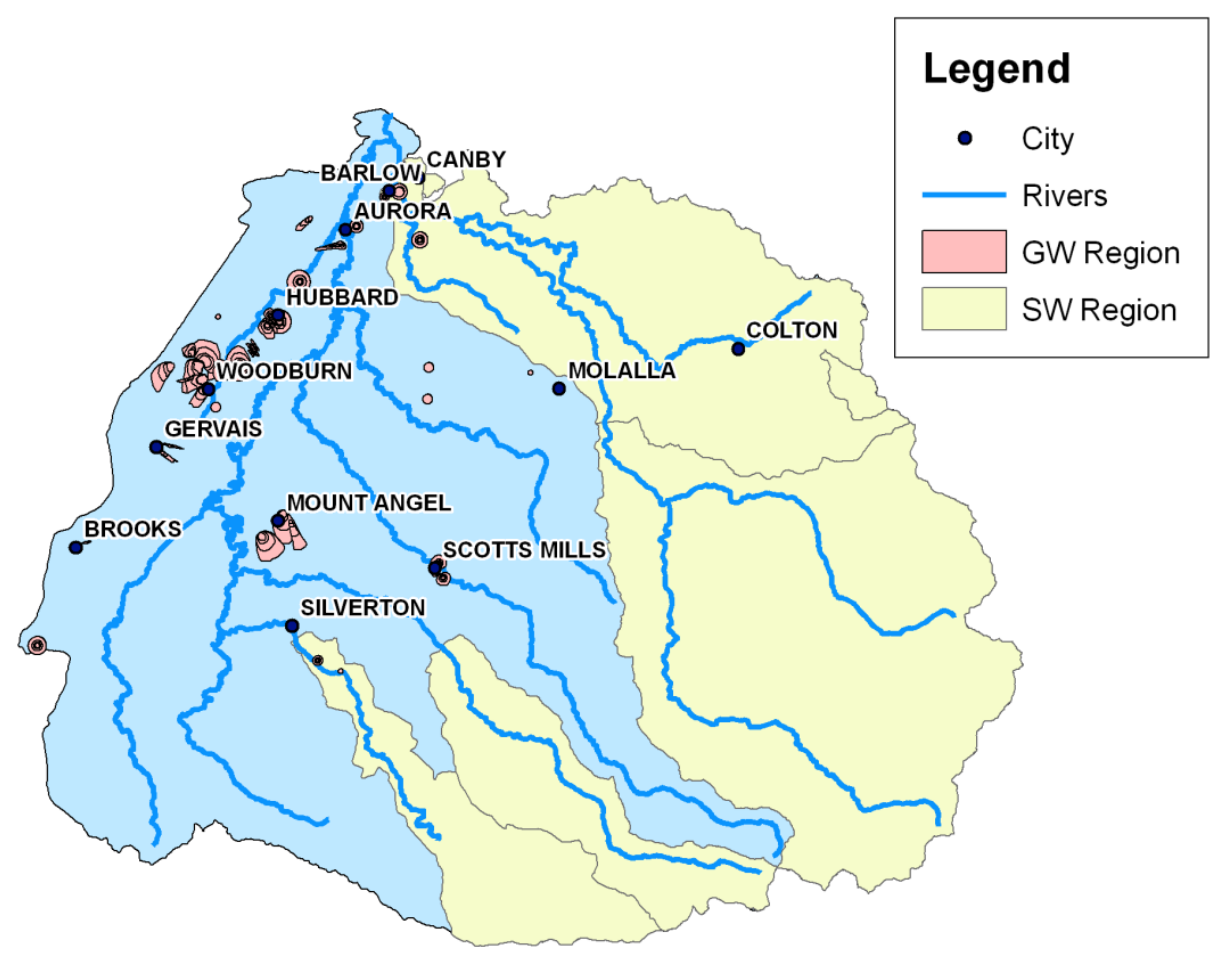

Figure 2: Protected ground and surface drinking water source areas.

\subsection{Datasets}

The observed data used for the drought analysis over the Molalla-Pudding basin was provided by the Western Regional Climate Center (WRCC) group. The WRCC provides monthly total precipitation and monthly mean maximum and minimum temperatures data for a number of gages throughout Oregon. The 10 gages selected for 
this study were located in Detroit, Estacada, McMinnville, Oregon City, Salem, Scotts Mills, Silver Creek Falls, Silverton and Stayton and the time period of interest was 19711998. As can be seen in table 1, the gages cover an elevation range of 150-2320 feet, which provides a good description of precipitation and temperature over the entire basin, from the forested mountains to the open valley. In order to evaluate general climate over the Molalla Pudding basin, the data were organized to describe its four quadrants: NW, NE, SW and SE.

Table 1: Observed data gage elevations.

\begin{tabular}{|l|c|}
\hline Gage & Elevation (feet) \\
\hline Detroit Dam & 1220 \\
\hline Estacada & 410 \\
\hline McMinnville & 150 \\
\hline Oregon City & 170 \\
\hline Salem & 210 \\
\hline Scotts Mills & 2320 \\
\hline Silver Creek Falls & 1350 \\
\hline Silverton & 410 \\
\hline Stayton & 430 \\
\hline N Willamette & 150 \\
\hline
\end{tabular}

The dynamically downscaled data used in this study were provided by the North American Regional Climate Change Assessment Program (NARCCAP), an international program funded by the National Science Foundation (NSF), the U.S. Department of Energy (US DOE), the National Oceanic and Atmospheric Administration (NOAA) and the U.S. Environmental Protection Agency Office of Research and Development to provide a high resolution climate change dataset for research on uncertainties in regional scale projections of future climate. NARCCAP uses a variety of regional climate models (RCMs) driven by atmospheric-ocean GCMs under the Special Report on Emissions 
Scenarios (SRES) A2 scenario to predict various climate variables. The SRES A2 scenario is generally considered to represent a high-end, although not the highest, greenhouse gas emissions scenario, and can present a future "worst-case" with continued increases in temperature. The historical period considered by NARCCAP was 19712000 and the future period considered was 2041-2070. The spatial resolution of all models was $50 \mathrm{~km}$ and the temporal resolution was variable-dependent; precipitation data were provided at 3-hour intervals, and temperature data was provided at daily intervals.

In this study, five datasets from NARCCAP were considered; three different RCMs and three different GCMs are represented. The first RCM includes data predicted by the HRM3 RCM driven by the HadCM3 GCM (both models developed by Hadley Centre), the second RCM is WRFG which was driven by the CCSM and CGCM3 GCMs and the third RCM is CRCM which was also driven by the CCSM and CGCM3 GCMs. Due to differing end dates in the NARCCAP model outputs, this study chose to focus on 28 year periods as all datasets included complete 28 year runs. So, the historical period considered by this research was 1971-1998 and the future period considered was 20412068. As can be seen in figure 3, the location of output gridpoints was not the same for all three RCMs so datapoints were averaged to produce values in the same quadrants as those defined for the observed data: NW, NE, SW and SE. 

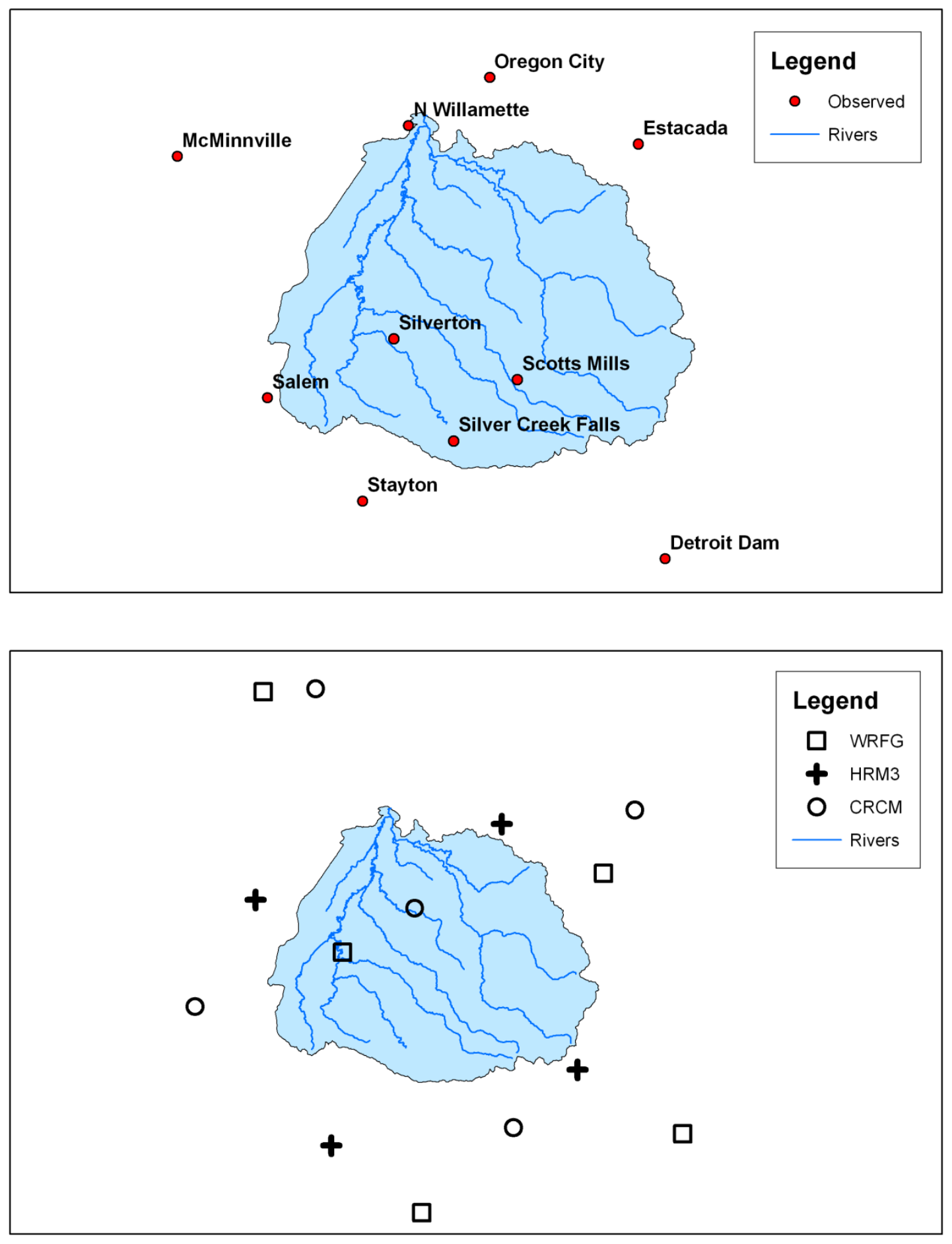

Figure 3: (Upper) Location of WRCC gages from which observed precipitation and temperature data were collected; (Lower) Location of grid points for the NARCCAP RCMs: WRFG, HRM3 and CRCM. 
In addition to the hydrologic data used to assess climate change and drive hydrologic models, streamflow data were collected to establish the baseline flow in the basin and to validate the hydrologic models. Streamflow data was acquired from the US Geological Survey for four different sites in the Mollala Pudding basin, two along the Molalla river and two along tributaries (Silver creek and Butte creek) of the Pudding river.

Table 2: USGS Stream gage records.

\begin{tabular}{|c|l|l|}
\hline USGS Gage & River & Period \\
\hline 14198500 & Molalla River near Wilhoit & $1971-1993$ \\
\hline 14200300 & Silver Creek at Silverton & $1971-1979$ \\
\hline 14201500 & Butte Creek at Monitor & $1971-1985$ \\
\hline 14200000 & Molalla River near Canby & $1971-1979$ \\
\hline
\end{tabular}

For water rights and water demand information, data were collected from the State of Oregon Water Resources Department's online Water Availability Reporting System

(http://apps.wrd.state.or.us/apps/wars/wars_display_wa_tables/search_for_WAB.aspx).

This tool provided the monthly natural flow, the monthly consumptive uses and storages and the monthly inflow requirement for habitat, for several creeks and river sections of the Molalla Pudding basin. The information was used to determine the water demand from various sectors (irrigation, agriculture, municipal) of the basin and those numbers were translated to the major cities of the basin. Overall, six reaches representing the Pudding river and its tributaries and five reaches representing the Molalla river and its tributaries were used to evaluate the water demand of the basin. 
Table 3: Reaches evaluated for water demand.

\begin{tabular}{|l|}
\hline Reach \\
\hline Abiqua creek to Pudding river, mouth \\
\hline Butte creek to Pudding river, mouth \\
\hline Milk creek to Molalla river, mouth \\
\hline Mill creek to Pudding river, mouth \\
\hline Molalla river above Gribble creek \\
\hline Molalla river above Milk creek \\
\hline Molalla river above N Fork Molalla river \\
\hline N Fork Molalla river to Molalla river, mouth \\
\hline Pudding river above Mill creek \\
\hline Pudding river above Howell Prairie \\
\hline Silver creek to Pudding river, mouth \\
\hline
\end{tabular}

The final data requirement for the calculation of water vulnerability indices was demographic information on the cities of the Molalla Pudding basin. This information was primarily acquired through the US Census Bureau's online fact finder tool (http://factfinder2.census.gov/faces/nav/jsf/pages/index.xhtml) for the year 2000, as that record was complete for all cities of interest. Additional information on the geography and land use of the basin was acquired from the Oregon Geospatial Enterprise Office. . 


\section{Chapter 2 Methods}

\subsection{Bias Correction}

Very often the process of downscaling data produces a fine resolution dataset that is similar to the observed data, but has a slightly different distribution, mean or standard deviation. The reasons for some of these differences come from biases found in the GCM and RCM used to produce the dataset. Removing or correcting these biases is useful in climate change studies because the purpose of the study is to evaluate changes in variability and spatial patterns of climate variables of interest (Johnson and Sharma, 2011). Additionally, bias correction allows datasets from multiple GCM-RCM combinations to be compared.

As will be seen in the Results section regarding validation of the climate data, the GCM-RCM model outputs required some correction. The NARCCAP datasets generally had medium to high correlation with observed data, but typically had different mean and standard deviations over the historical period. Additionally, the distributions of the NARCCAP climate variables were similar to, but not exactly similar to those from observed data. For this reason, the precipitation and temperature outputs from the NARCCAP data were all bias corrected before performing analyses.

Since the NARCCAP data was well correlated with the observed data, the bias correction procedure used in this study was quite simple, and aimed to readjust the NARCCAP data to match the monthly mean and monthly standard deviation over the historical period. Future data were also bias corrected using a similar equation, which maintained the differences in monthly means and standard deviations between the 
historical and future periods. Other advanced methods of bias correction, like quantile mapping, were not used in this work due to their assumption of historical and future datasets sharing the same probability distribution. The benefit of using dynamically downscaled data was the independence from statistical assumptions, and that independence needed to be preserved through the bias correction procedure.

The bias correction was performed as so. For a variable, V, with historical modeled monthly mean $\mathrm{V}_{\text {hist,avg, }}$, historical modeled monthly standard deviation $\mathrm{V}_{\text {hist,sd, }}$ observed monthly mean $\mathrm{O}_{\text {avg }}$ and observed monthly standard deviation $\mathrm{O}_{\mathrm{sd}}$, the historical and future bias corrected values, $\mathrm{V}_{\text {hist,bc }}$ and $\mathrm{V}_{\text {fut,bc }}$ respectively, were calculated as:

$$
\begin{gathered}
V_{\text {hist }, b c}=\frac{V_{\text {hist }}-V_{\text {hist }, \text { avg }}}{V_{\text {hist }, \text { sd }}} O_{s d}+O_{\text {avg }} \\
V_{f u t, b c}=\frac{V_{\text {fut }}-V_{\text {hist }, \text { avg }}}{V_{\text {hist }, \text { sd }}} O_{s d}+O_{\text {avg }}
\end{gathered}
$$

The calculations were performed on monthly values (cumulative precipitation, average maximum temperature and average minimum temperature) to produce a monthly bias corrected dataset which could be compared to other GCM-RCM datasets and could be analyzed using established hydrology techniques to detect status and trend.

This particular bias correction method was selected as the computation procedure was relatively simple and because the procedure did not make the assumption that historical and future data had the same distributions. As will be shown in the results section, the distributions for bias corrected future variables were different than the distributions over the historical period. This information provided another perspective 
when considering climate change impacts and the occurrences of extreme events. Additionally, when compared with other bias correction and scaling techniques (Johnson and Sharma, 2011) this monthly bias correction method performed well and produced datasets with little error. This method performed particularly well with respect to reproducing the monthly mean, monthly median, annual mean and annual median of corrected datasets.

\subsection{Drought Index}

For this study, accumulated monthly precipitation deficit indices were used as drought indictors (Bryant et al., 1998; Philips and MacGregor, 1998). The benefit of using precipitation deficit indices was that precipitation was the only input variable. For a climate change study this was ideal, as the indices represented the uncertainty of only one variable as opposed to many. This was particularly desirable for a dataset downscaled to mid-level resolution over a large area. Additionally, simple indices relying only on precipitation were been found to work comparatively well to more complicated indices, such as the Palmer Drought Severity index (Oladipo, 1985). The precipitation deficit indices presented in this paper, have been used widely in Europe for some time (Blenkinsop and Fowler, 2006; Fowler and Kilsby, 2004), but have not been as widely applied in American research. The two indices used in this study evaluate the 3-month deficit (DSI3) and 6-month deficit (DSI6) periods to determine general drought events and extreme drought events.

The procedure to calculate the indices is fairly straightforward, and can be carried out in a spreadsheet format or with statistical computing software. First, monthly 
precipitation anomalies with respect to the 1971-2000 mean were calculated. The DSI3 relied on a 3-month initiation and termination rule, so if one considered the anomaly in month $t$ as $\mathrm{X}_{\mathrm{t}}$, a drought would initiate in month $t$ if the sum of $\mathrm{X}_{\mathrm{t}}, \mathrm{X}_{\mathrm{t}-1}$ and $\mathrm{X}_{\mathrm{t}-2}$ were less than its 3-monthly mean (or if the accumulated deficit were negative). The index value assigned at time $t$ would be a positive value equal to the deficit in month $t$. Next, month $t+l$ was considered. If the next month also had a negative precipitation anomaly and if the sum of $X_{t-1}, X_{t}$ and $X_{t+1}$ were less than its 3-monthly mean (accumulated deficit was negative), then the drought continues and the index at time $t+1$ were the positive value equal to the sum of the deficits in months $t$ and $t+1$. Now, if month $t+1$ had a positive precipitation anomaly, but the sum of $\mathrm{X}_{\mathrm{t}-1}, \mathrm{X}_{\mathrm{t}}$ and $\mathrm{X}_{\mathrm{t}+1}$ were still less than the 3-monthly mean, the drought would continue but the index would be the positive value equal to the difference of the deficits in months $t$ and $t+1$. The drought would be terminated when the 3-monthly mean was exceeded by the sum of the preceding precipitation anomalies. The DSI6 would be calculated in the same way as the DSI3, but would use 6-month initiation and termination periods. This DSI6 would be considered comparable to a hydrologic drought.

In order to compare indices from various quadrants of the study basin, all deficit values were standardized by dividing the absolute deficit by the total annual precipitation for that dataset. This provided the drought index as a percentage deficit which enabled inter-quadrant comparisons. Following the procedure used by Fowler and Kilsby (2006), DSI3 indices with values greater than 10\% indicated a 3-6 month drought event that would be likely to affect surface water resources. Similarly following Fowler and Kilsby 
(2006), DSI6 indices with values greater than 30\% indicated serious droughts lasting at least 6 months that were more likely to affect groundwater resources.

\subsection{Hydrologic Modeling}

The hydrologic model used in this study was the Precipitation-Runoff Modeling System (PRMS) which was developed by the US Geological Survey. PRMS is described as a "modular deterministic, distributed-parameter, physical-process watershed model" and was used to simulate runoff through a series of surface and groundwater reservoirs. PRMS modeling evaluates the lateral and vertical interactions between hydrologic response units (HRU) to determine the amount of water within the subsurface and the amount lost from the basin as surface runoff or evaporation. PRMS relies on information about land use, impermeable surface, vegetation canopy, soil type and hydrology to perform mass balance calculations on a daily time step.

The PRMS model routes water from upstream HRUs to downstream HRUs, streams or lakes. Additionally, water is brought onto the HRU by precipitation and can infiltrate to the subsurface reservoir or leave the HRU surface by evapotranspiration due to temperature and solar radiation. Potential evapotranspiration is calculated by the Hamon formulation, which relies on a calibrated HRU parameter, HC, saturated watervapor density, $\rho$, as calculated by air temperature and the possible number of hours of sunlight, sh (Markstrom et al., 2008):

$$
P E T=H C\left(\frac{s h}{12}\right)^{2} \rho
$$

The water remainder contributes to surface runoff or infiltration, which are computed by antecedent soil moisture and a non-linear variable source area method. 
Runoff over pervious area is calculated by a Hortonian runoff method in which contributing runoff area, $F_{\text {perv }}$, is that where throughfall is greater than the soil infiltration rate. Runoff, RO, is then calculated from upstream HRU runoff and precipitation as (Markstrom et al., 2008):

$$
R O=F_{\text {perv }}\left(R O_{u p}+P\right)
$$

Water not contributing to runoff, qsi, can infiltrate the soil by the following equation, where $\mathrm{V}_{\mathrm{SM}}$ is the volume of melted snowpack and $\mathrm{A}$ is the pervious area of the HRU. In this equation, the amount of water infiltrating is the difference between the total amount of water coming into the basin and the runoff out of the basin (Markstrom et al., 2008):

$$
q s i=\left(R O_{u p}+\frac{V_{S M}}{A}+P-R O\right) * A
$$

Infiltrated water is then partitioned between the preferential flow reservoir, for fast-flowing interflow through large pore spaces, the capillary reservoir and the gravity reservoir.

For this study, an existing calibrated PRMS model of the Molalla Pudding basin was used to perform hydrologic modeling over historical and future periods. The Molalla Pudding PRMS model was first developed by the US Geological Survey in 1997 as part of a study to evaluate the hydrology of the whole Willamette basin (Laenan and Risley, 1997). The Willamette PRMS model was updated five years later to refine the basin delineations and to include updated land surface map information (Lee and Risley, 2002). Finally, in 2010 the Willamette PRMS model was updated further to run compatibly with the latest version of PRMS and recalibrated to include relevant and updated snow 
parameter data, digital elevation model, soil information, land use/cover and geology (Jung and Chang, 2010).

For this study, the model was validated over the historical period of 1971-1998 by comparing runoff results to USGS gage streamflow. The validated model was then run with the predicted NARCCAP data variables, precipitation, maximum temperature and minimum temperature, to determine changes in future runoff. These modeled values, over both the historical and future periods, were included in the development of water vulnerability indices that allowed ranking of vulnerability of the Molalla Pudding cities. 


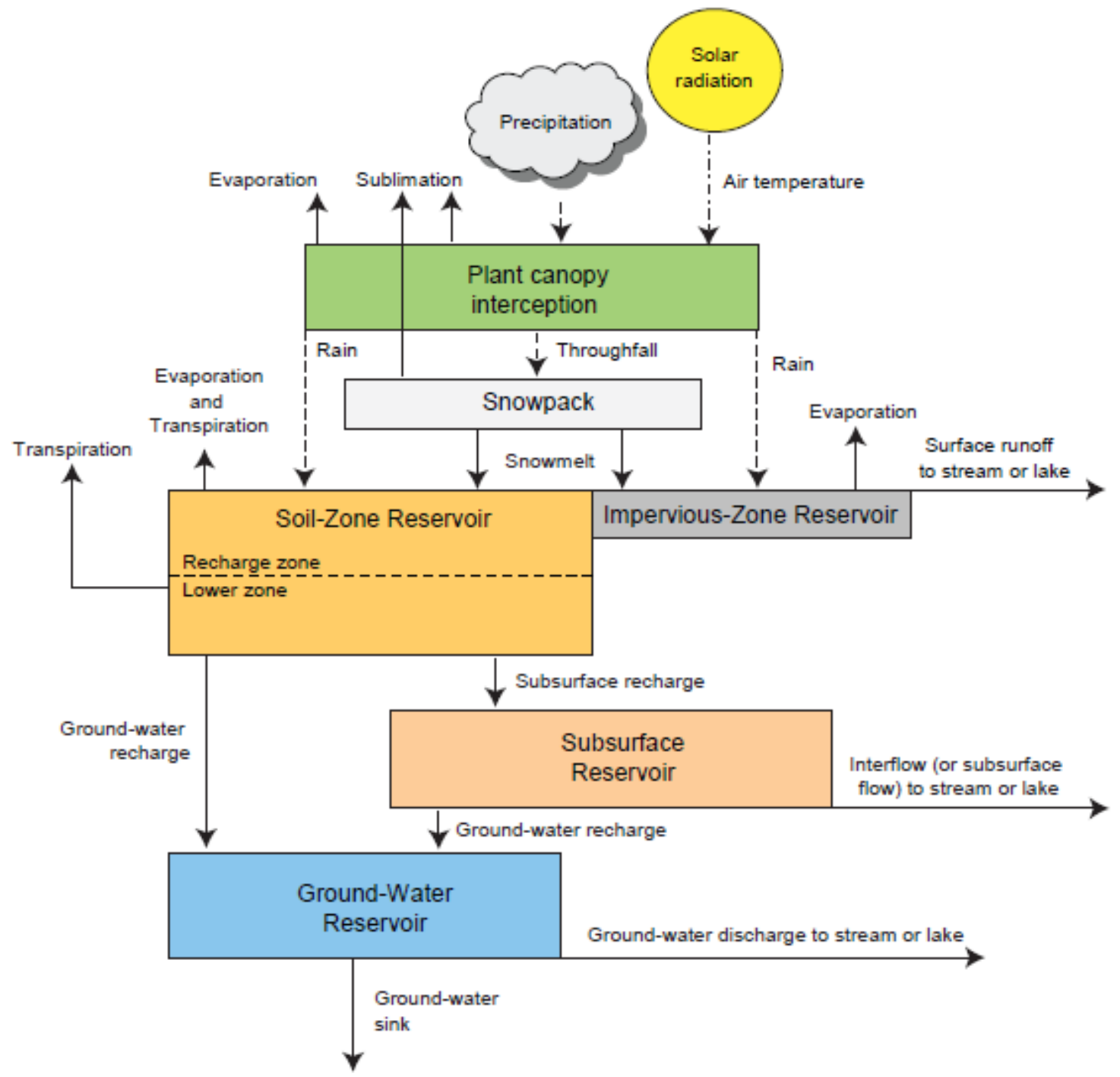

Figure 4: Schematic of the PRMS model water balance system (Markstrom et al., 2008). 


\subsection{Water Vulnerability Index}

The first water vulnerability index (WVI) considered in this study was one presented by Sullivan (2011) to evaluate scarcity in southern Africa. The WVI was separated into two components: supply driven vulnerability and demand driven vulnerability. As their names would suggest, the supply component reflects the vulnerability of the water system itself, while the demand component reflects vulnerability of water users. The total WVI is a sum of the supply and demand components.

Sullivan describes supply driven vulnerability through the categories of resource vulnerability, extreme event vulnerability, land cover vulnerability and storage vulnerability, while demand driven vulnerability is described through by the categories of demographic vulnerability, household vulnerability, economic vulnerability and bulk demand vulnerability. The specific variables used to quantify these categories were modified for this study in order to capture the most value from the available datasets, and deviated slightly from Sullivan's.

For supply driven vulnerability (SDWV), seven total variables were used. Resource vulnerability was described by mean annual runoff (R) and protected groundwater area per capita $(\mathrm{GW})$, where runoff was an output from the PRMS hydrologic model. Extreme event vulnerability was described by the number of months having less than 18.4 cumulative millimeters of precipitation $(\mathrm{Z})$ and by the number of months having more than 263.6 cumulative millimeters of precipitation (Ex). These thresholds were determined by fitting observed monthly precipitation data with a gamma 
distribution and finding the $10 \%$ and $90 \%$ probabilities of exceedance. Land cover vulnerability was described as the percentage of upstream area with impervious surfaces (UU) and as the percentage of water diverted for irrigation and agriculture (I) within a city's subbasin. Finally, storage vulnerability was described by the coefficient of variation $(\mathrm{CV})$ (standard deviation/mean) of precipitation.

For demand driven vulnerability (DDWV), six total variables were used. Demographic vulnerability was described by total population (TP) and population density (PD), while household vulnerability was described by the percent of the population living in poverty (EC). Economic vulnerability was described by the percentage of the population working in water-dependent sectors, including agriculture, mining, and manufacturing (EMP). Bulk demand vulnerability was described by the total annual water demand (DEM), which was determined by evaluation of historic demand. Finally, ecological demand was described by a maximum 7-day stream temperature average as observed over the period May-October 2004 (T).

All variables that were not already represented as percentage values were normalized and inverted if a high value did not indicate vulnerability. Each of the variables also received weights, $r$, that denoted risk giving rise to vulnerability, however, for this preliminary assessment all variables received a weight of one. The equations for the SDWV, DDWV and the WVI were then:

$$
S D W V=\frac{r_{M} M+r_{G W} G W+r_{Z} Z+r_{E x} E x+r_{U U} U U+r_{I} I+r_{C V} C V}{r_{M}+r_{G W}+r_{Z}+r_{E x}+r_{U U}+r_{I}+r_{C V}}
$$




$$
\begin{gathered}
D D W V=\frac{r_{T P} T P+r_{P D} P D+r_{E C} E C+r_{E M P} E M P+r_{D E M} D E M+r_{T} T}{r_{T P}+r_{P D}+r_{E C}+r_{E M P}+r_{D E M}+r_{T}} \\
W V I=S D W V+D D W V
\end{gathered}
$$

\subsection{Social Vulnerability Index with Water Components}

The second vulnerability index considered in this study was an adaptation of the Social Vulnerability Index (SOVI) that was developed by the US Army Corps of Engineers (USACE) in response to the devastation of Hurricane Katrina (Dunning and Durden, 2011). SOVI evaluates nine categories of social vulnerability through thirty different variables, described in table 4, that were acquired through the 2000 US Census. The nine categories described by SOVI are age, income/poverty, minority status, disabled, employment, mobile homes/renters, gender, education and density. Since SOVI does not include specific variables relating to water demand and water supply, this study expanded on the index by adding several of the variables from the WVI analysis and drought information.

The specific WVI variables added to SOVI were runoff, groundwater storage, low precipitation events, extreme precipitation events, percentage impervious area, percentage of water diverted for agriculture, precipitation coefficient of variation, total water demand and total evaporative demand. Drought indices were also added to SOVI by including the number of events, length of events and intensity of events as determined by the DSI3 and DSI6 evaluations. Once all of the contributing variables had been collected for each of the twelve Molalla Pudding cities, the data were organized in a 
matrix by city and evaluated by Principal Components Analysis (PCA) with varimax rotation of the loading matrix.

PCA is a technique used to reduce the dimensionality of a dataset while retaining most of its intrinsic information content (Haykin, 1999). For a dataset described by matrix, $\mathrm{X}$, with a nonzero mean the PCA technique determines a weighting or loading matrix, w, which projects the dataset into the principal component space, A, where the variance along each component is maximized:

$$
A=X^{T} w=w^{T} X
$$

The matrix A has the same statistical characteristics as the original matrix, $\mathrm{X}$, and so it could be seen that the variance of the dataset is represented by the expected value of the matrix, $\mathrm{A}^{2}$. Relying on substitution, the covariance matrix, $\mathrm{R}$, of the dataset $\mathrm{X}$ can be included in the calculation as so (Haykin, 1999):

$$
\sigma^{2}=E\left[A^{2}\right]=E\left[\left(w^{T} X\right)\left(X^{T} w\right)\right]=w^{T} E\left[X X^{T}\right] w=w^{T} R w
$$

In order to determine the values of $\mathrm{w}$ that will diagonalize the covariance matrix, or maximize the variance within each component and minimize the covariance between components, the matrix w must be composed of orthogonal components (Haykin, 1999). Another way of describing this mathematically is to say the weighting matrix, w, and the covariance matrix, $\mathrm{R}$, must satisfy the following relation for some diagonal matrix, $\mathrm{B}$ :

$$
R w=B w
$$

If the matrix $\mathrm{B}$ is instead represented by a scalar vector, $\mathrm{b}$, comprised of the diagonal values of $\mathrm{B}$, the equation represents the unique relationship between eigenvectors, $\mathrm{w}$, and eigenvalues, $\mathrm{b}$ : 


$$
R w=b w
$$

Therefore, determining the eigenvectors, w, and eigenvalues, b, of a covariance matrix, $\mathrm{R}$, will result in determining a weighting matrix, w, which has orthogonal components and which will maximize the variance of those components. Applying the weighting matrix to the original dataset will produce a set of principal components that are uncorrelated, orthogonal, and which can be selected based on the amount of variance described. The principal components associated with eigenvalues greater than one are selected based on the Kaiser criterion (Kaiser, 1960).

In order to better understand the structure of the dataset, rotation of the principal component axes was performed by varimax rotation (Kaiser, 1958). Varimax rotation rotates the axes so that variance is maximized and the loadings matrix has very large and very small values. This technique makes clearer the variables associated with the principal component axes. The varimax rotation is used here to determine which components are associated with which SOVI variables. Analysis of the types of variables associated with a component can establish whether or not that component indicates vulnerability. For example, a component that was highly correlated with poverty and unemployment would indicate vulnerability and higher values of the dataset along that component would indicate greater vulnerability. In this way, each component can be evaluated to determine whether its scores should be added or subtracted to determine a vulnerability score.

The SOVI+Water Component vulnerability index is computed by either adding or subtracting the component scores for each city such that higher component scores 
indicate greater vulnerability. Since this index is calculated based on the relationships within the dataset itself, the vulnerability score is only meaningful with respect to the dataset used in the analysis. The values of the indices do not have a specific meaning that can be evaluated from empirical tables; they can only be used to rank and compare the sites included in the dataset. 
Table 4: Social vulnerability factors considered for the SOVI + WC.

\begin{tabular}{|c|c|c|}
\hline Variable name & Description & $\begin{array}{l}\text { Vulnerability } \\
\text { dimensions }\end{array}$ \\
\hline MEDAGE & Median age & Age \\
\hline QKIDS & Percent of population under 5 years of age & Age \\
\hline QPOP65 & Percent of population 65 and over & Age \\
\hline QSSBEN & $\begin{array}{l}\text { Percent of population collecting social security } \\
\text { benefits }\end{array}$ & Age, income/poverty \\
\hline QBLACK & Percent African American & Minority status \\
\hline QINDIAN & Percent Native American & Minority status \\
\hline QASIAN & Percent Asian and Hawaiian Islanders & Minority status \\
\hline QSPANISH & Percent Hispanic & Minority status \\
\hline MIGRA & Foreign born & Minority status \\
\hline NRRESPC & Per capita residents in nursing homes & Age, disabled \\
\hline QRENTER & Percent renter-occupied housing units & $\begin{array}{l}\text { Mobile } \\
\text { Homes/renters }\end{array}$ \\
\hline QMOHO & Percent of housing units that are mobile homes & $\begin{array}{l}\text { Mobile } \\
\text { Homes/renters } \\
\end{array}$ \\
\hline PERCAP & Per capita income & Income/poverty \\
\hline MHSEVAL & Mean value of owner-occupied housing units & Income/poverty \\
\hline M_C_RENT & Mean contract rent & Income/poverty \\
\hline QRICH & Percent of households earning $\$ 100,000$ or more & Income/poverty \\
\hline QPOVTY & Percent living below poverty level & Income/poverty \\
\hline PPUNIT & Average number of people per household & Income/poverty \\
\hline QCVLUN & Percent civilian unemployment & Employment \\
\hline QCVLBR & $\begin{array}{l}\text { Percent of population participating in the labor } \\
\text { force }\end{array}$ & Employment \\
\hline QAGRI & $\begin{array}{l}\text { Percent employment in farming, fishing, and } \\
\text { forestry occupations }\end{array}$ & Employment \\
\hline QTRAN & $\begin{array}{l}\text { Percent employment in transportation, } \\
\text { communications, and other public utilities }\end{array}$ & Employment \\
\hline QSERV & Percent employed in service industry & Employment \\
\hline QFEMLBR & Percent females participating in the labor force & Employment, gender \\
\hline QFEMALE & Percent female population & Gender \\
\hline QFHH & $\begin{array}{l}\text { Percent female-headed household, no spouse } \\
\text { present }\end{array}$ & $\begin{array}{l}\text { Gender, } \\
\text { income/poverty }\end{array}$ \\
\hline QED12LES & $\begin{array}{l}\text { Percent of population } 25 \text { years or older with no } \\
\text { high school diploma }\end{array}$ & Education \\
\hline HODENT & Number of housing units per square mile & Density \\
\hline QRFRM & Percent rural farm population & Density, rural status \\
\hline QURBAN & Percent urban population & Density, urban status \\
\hline
\end{tabular}




\section{Chapter 3 Results}

\subsection{Data Validation}

Before calculating drought indices or running hydrologic models, the downscaled NARCCAP data need to be validated against historical observations. Evaluation of status and trend were completed by comparing data means, data distributions, trends and Pearson correlation coefficient over the period 1971-1998. While the models generally had good correlation for all variables, the decision to bias correct all NARCCAP data was made due to the significant differences in mean values and in distributions.

The NARCCAP precipitation data generally had good correlation (0.42-0.61) over the historical period for all quadrants of the Molalla Pudding basin. The means and distributions, however, displayed the lack of NARCCAP data to match the observed precipitation record. The observed data indicated that mean annual precipitation over the basin was 1390-2196 mm per year, while the NARCCAP models had varying spatial disagreements with that value. The two CRCM records generally had little variation between the annual precipitation (1488-1775 mm/year) of the quadrants and did not describe the full variability of the system. The HRM3 model, on the other hand, modeled too much variability with quadrant precipitation ranging 547-3017 mm/year. The WRFG datasets had good variability, but overestimated precipitation in the western half of the basin and underestimated precipitation in the eastern half of the basin. Additionally, figure 5 demonstrates the inability of any of the NARCCAP datasets to capture the precipitation distribution observed for each quadrant. 
The NARCCAP maximum and minimum temperature data, with the exception of the HRM3-HadCM3 model, had high correlations (0.71-0.93) over the historical period for all quadrants. From the historical records, average maximum temperatures ranged 14.6- $16.4^{\circ} \mathrm{C}$ and average minimum temperatures ranged $5.06-5.37^{\circ} \mathrm{C}$. Much like the precipitation records, the CRCM datasets underestimated the mean maximum temperature $\left(13.4-15^{\circ} \mathrm{C}\right)$ and mean minimum temperature $\left(2.43-4.48^{\circ} \mathrm{C}\right)$ by $1-2$ degrees and overestimated the temperature variability for all quadrants. The HRM3 model overestimated the mean maximum temperature $\left(16.1-20.8^{\circ} \mathrm{C}\right)$ and the mean minimum temperature $\left(5.56-9.24^{\circ} \mathrm{C}\right)$ by several degrees and also overestimated the temperature variability. The WRFG datasets also underestimated both the mean maximum temperature $\left(6.5-14.2^{\circ} \mathrm{C}\right)$ and the mean minimum temperature $\left(1.96-4.75^{\circ} \mathrm{C}\right)$ values, while overestimating the temperature variability across the Molalla Pudding quadrants. Figures 6 and 7 demonstrate the inability of NARCCAP datasets to capture the temperature distributions observed over the Molalla Pudding basin.

Since the NARCCAP datasets present different historical means and distributions from the observed dataset, the decision to perform bias correction was made. Since the NARCCAP sets do show high correlation with the observed data, a relatively simple bias correction method can be used to shift and adjust the data to match the observed mean and standard deviation. 

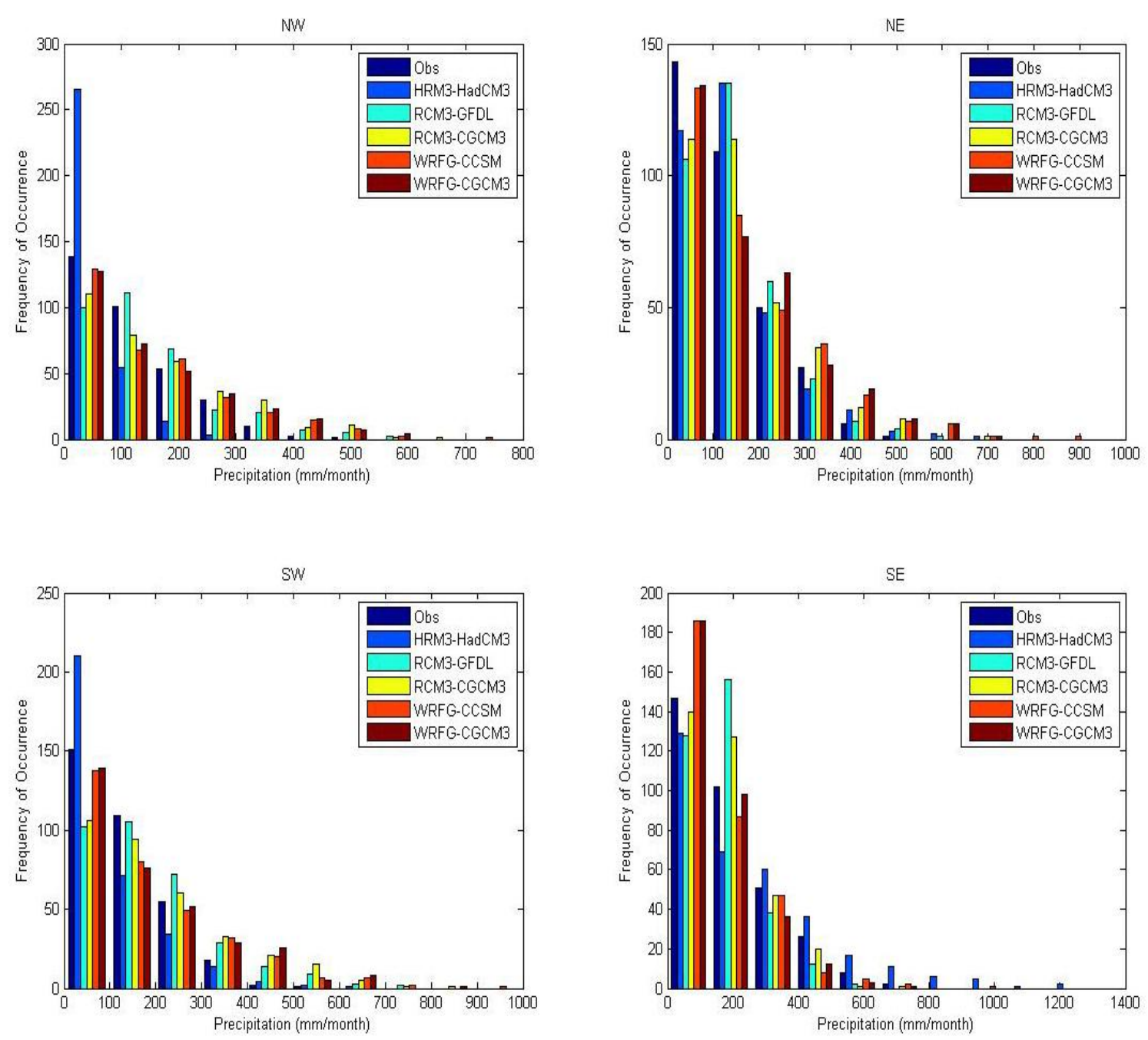

Figure 5: Precipitation distributions over 1971-1998 before bias correction. 

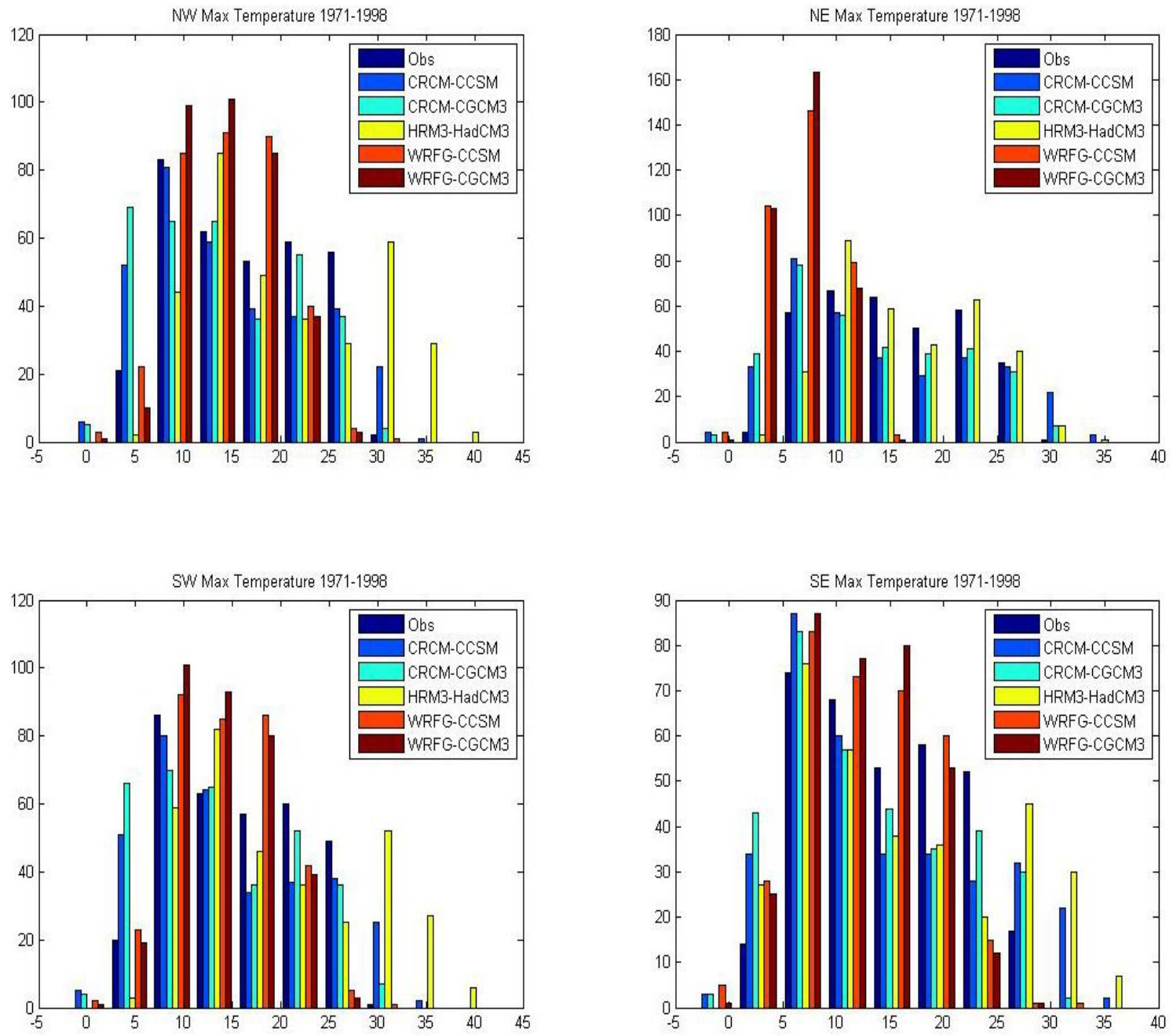

Figure 6: Maximum temperature distributions over 1971-1998 before bias correction 

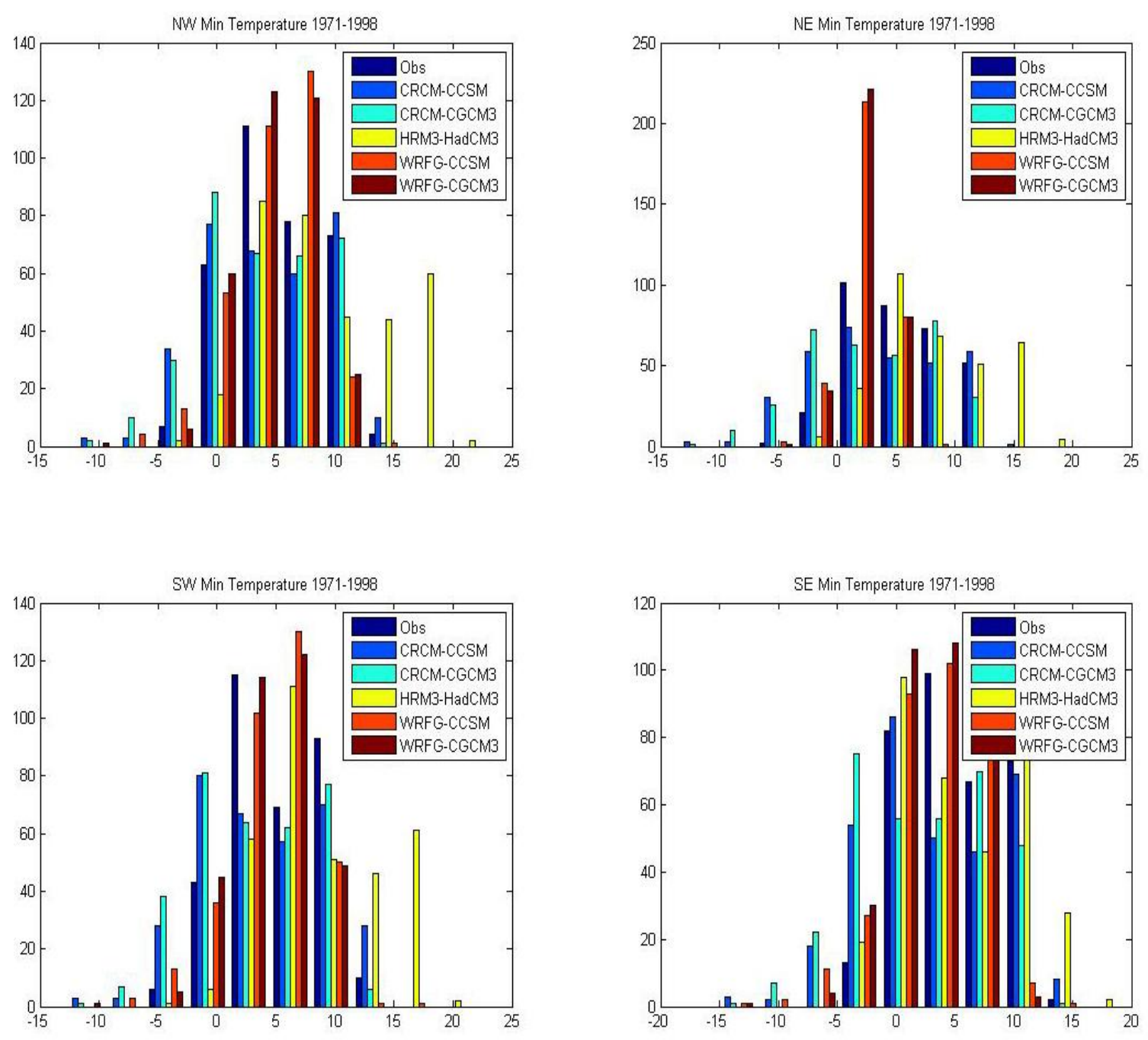

Figure 7: Minimum temperature distributions over 1971-1998 before bias correction. 


\subsection{Bias Correction}

As can be seen in figures 8-10, the bias correction of NARCCAP precipitation and temperature data resulted in datasets that better matched the status and trend of the observed data over 1971-1998. Precipitation shows good correlation (0.47-0.56) and temperature shows high correlation (0.90-0.94) for all NARCCAP models. Additionally, the annual means and the probability distributions in the historical NARCCAP data now match the observed data.

The trends in the historical datasets were also compared using the Mann-Kendall statistic. Observed precipitation shows a slight decreasing trend over 1971-1998 and observed temperature shows a significant increasing trend over 1971-1998. The biascorrected NARCCAP precipitation data also shows a slight decreasing trend, except for two datasets in the NW quadrant. Since the magnitude of the trend is quite small, this discrepancy is not considered to be significant. For temperature, the NARCCAP data consistently shows agreement with the large increasing trend seen in the observed dataset. Interestingly, the observed data and NARCCAP sets both show much greater increases in minimum temperature than in maximum temperature. 

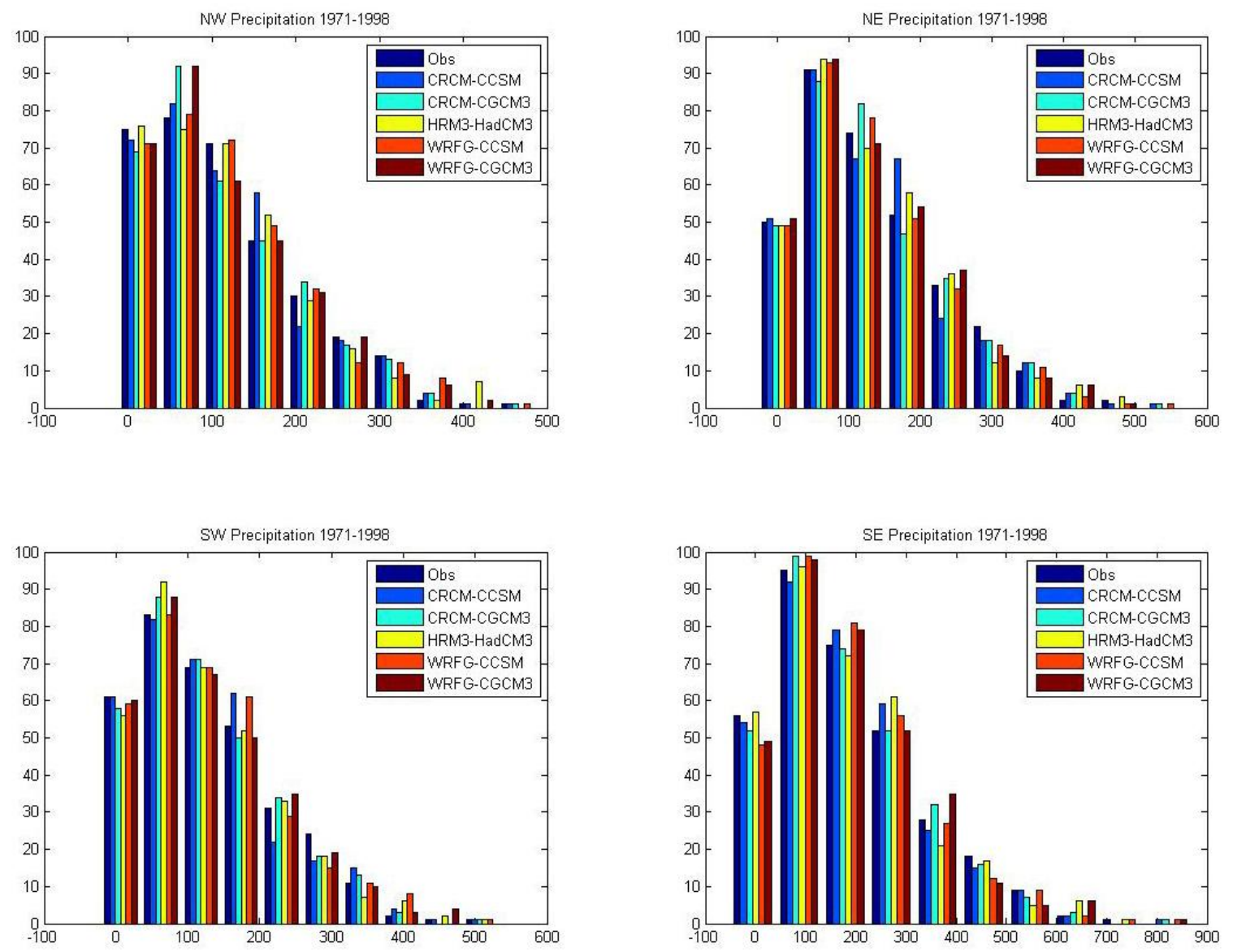

Figure 8: NARCCAP precipitation distributions over 1971-1998 after bias correction. 

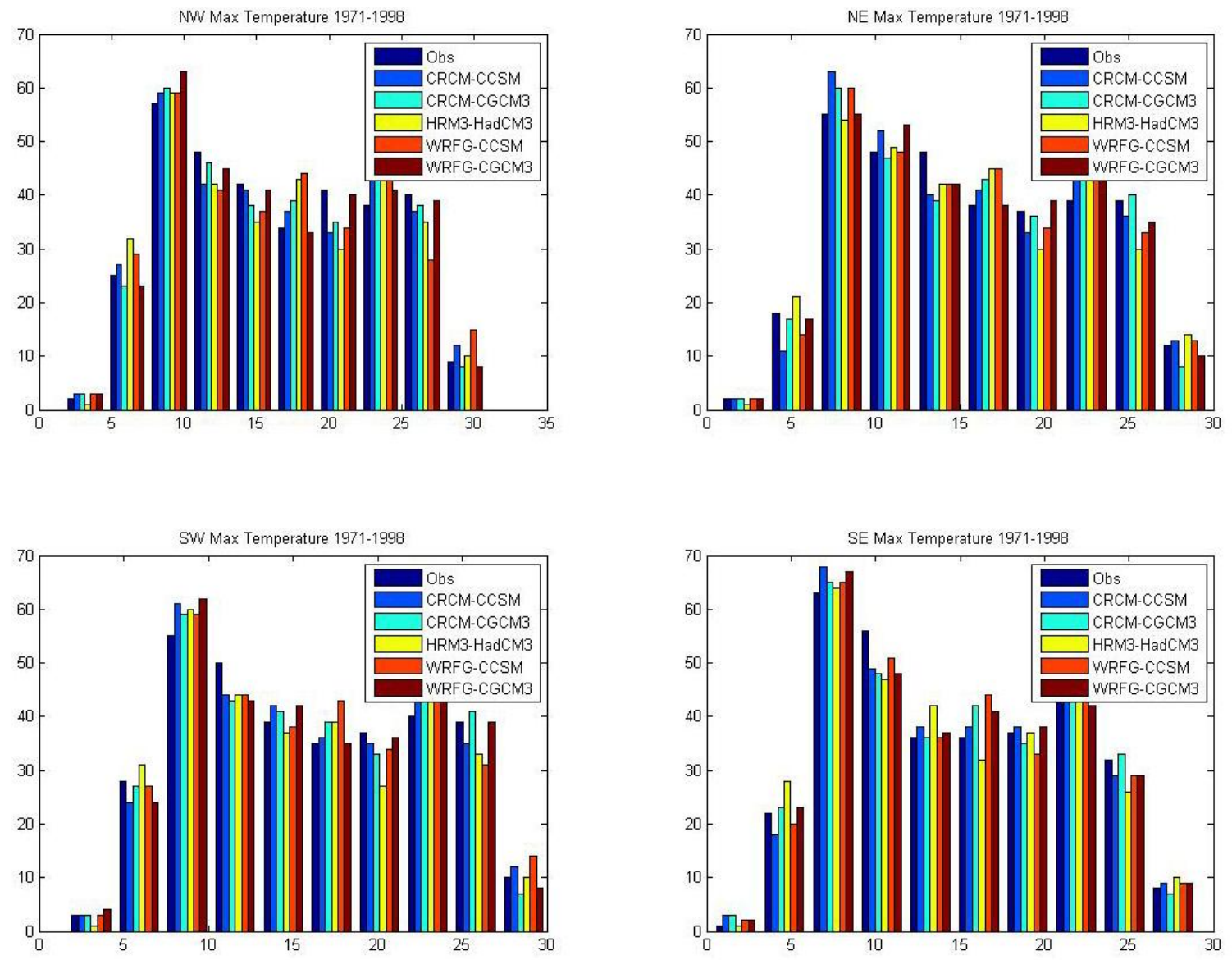

Figure 9: NARCCAP maximum temperature distributions over 1971-1998 after bias correction. 

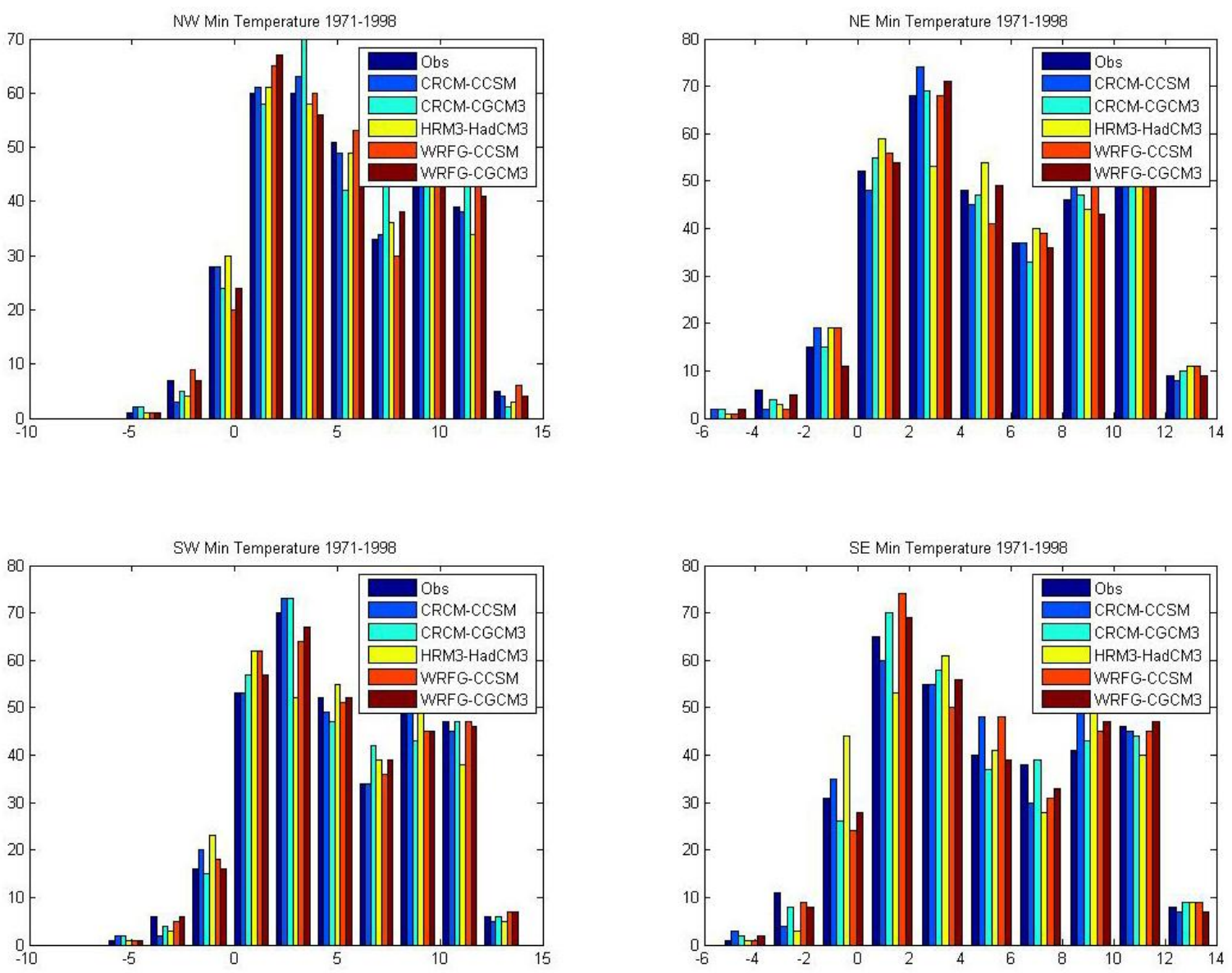

Figure 10: NARCCAP minimum temperature distributions over 1971-1998 after bias correction. 


\subsection{Climate Change Evaluation}

Once the NARCCAP precipitation and temperature data were downscaled, assessments of climate change in the Molalla-Pudding basin could be made. Overall, the five $\mathrm{RCM} / \mathrm{GCM}$ combinations were in agreement as to the change in status and trend in the two variables considered. There were discrepancies between models that will be discussed in the following sections, but generally the NARCCAP data for the future period 2041-2068 was consistent.

Only the WRFG-CCSM model showed a significant decrease in future precipitation, the remaining four models showed either no change (CRCM-CCSM) or increases in precipitation. The greatest changes were seen in the eastern half of the basin (+100-200 mm/year), suggesting the models were influenced by the hydrology of the Cascade Mountain ranges and a potential for increased mountain runoff. Evaluations of the future trend of precipitation were also considered by the Mann Kendall test and overall the models show agreement in the increasing trend of precipitation for future years.

For temperature changes in 2041-2068, all models showed increases in both maximum and minimum temperatures. For the most part, all models showed greater increases in minimum temperature $\left(+1.51^{\circ} \mathrm{C}\right)$ than in maximum temperature $\left(+1.42^{\circ} \mathrm{C}\right)$. The NARCCAP models also have agreement in the significant increasing trend in future precipitation, as determined by the Mann Kendall test. While the future increasing trends are high they are not as high as the increasing trends over the historical period. This could represent a leveling off of future temperature that many climate models are predicting. 

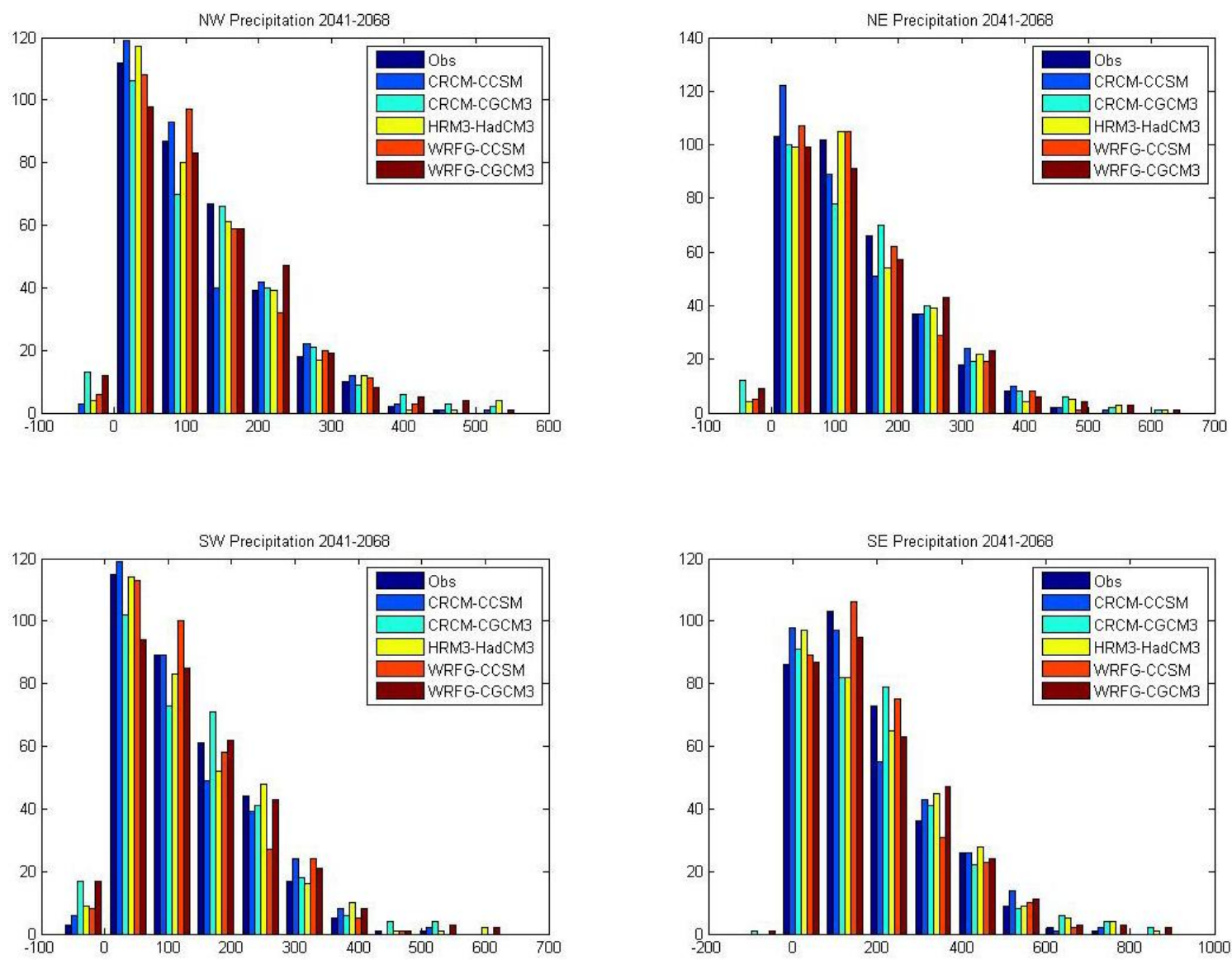

Figure 11: NARCCAP precipitation distributions over 2041-2068 after bias correction. 

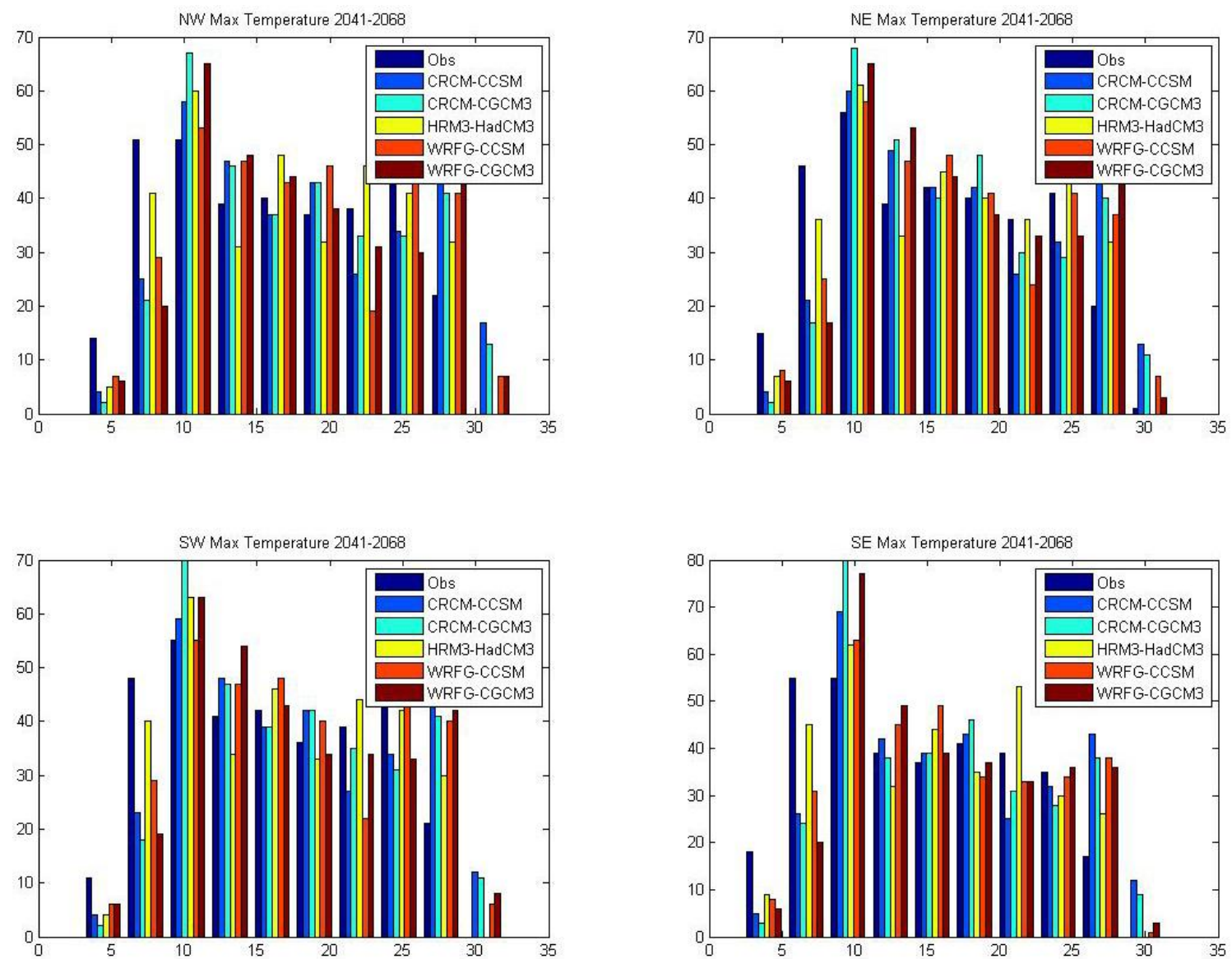

Figure 12: NARCCAP maximum temperature distributions over 2041-2068 after bias correction. 

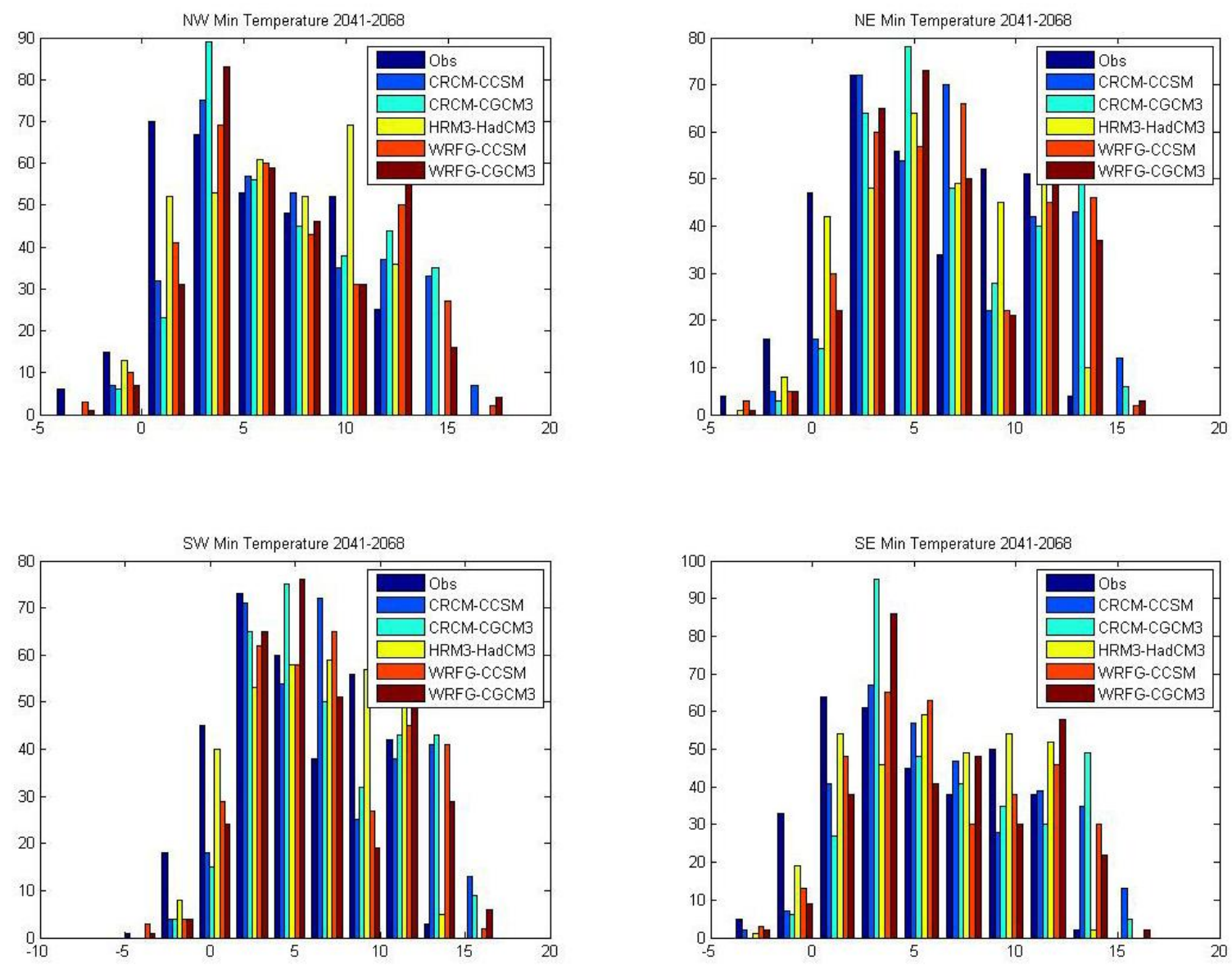

Figure 13: NARCCAP minimum temperature distributions over 2041-2068 after bias correction. 


\subsection{Drought Indices}

Using the DSI3 and DSI6 drought indices discussed in the methods section, the historical and future precipitation data were evaluated to determine expected changes in drought occurrences, drought length and drought intensity (as a percentage of mean annual precipitation). First, the indices were applied to the observed data in the four quadrants of the Molalla-Pudding basin. Over the 28 year historical period, the basin experienced 11-12 drought events and 4-5 serious drought events, depending on the quadrant. The average duration for the minor events was $\sim 6.7$ months, while the average duration for the serious events was $\sim 4.9$ months. The intensity of the drought events was measured as the percent deficit with respect to mean annual precipitation; the minor events had average intensities of $21 \%$ and the serious events had average intensities of $36 \%$ over the historical period. The drought events calculated using the NARCCAP data matched the observed drought statistics well.

For minor events, the NARCCAP models tend to predict a decrease in the number of events. The average across the basin results in a decrease of 2 events for 2041-2068. For serious events, the NARCCAP models show less agreement. Several models predict either no change in the number of serious events, or small changes of \pm 1 , which leads to an inconclusive understanding of future occurrences. Since there are no significant increases or decreases, the prediction of this study is that there will be no change in the number of these serious drought events. 


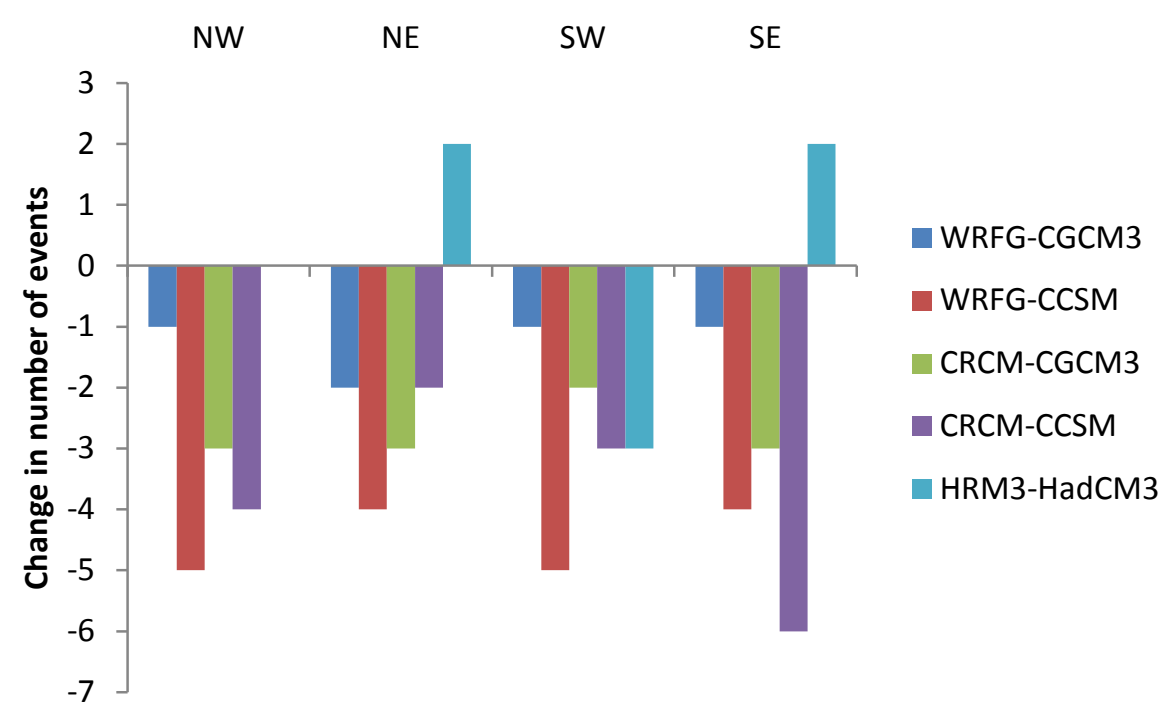

Figure 14: Change in the number of drought events from 1971-1998 to 2041-2068.

While there is expected to be a slight increase in the number of minor drought events, the duration of these events is not expected to change by more than a month. The NARCCAP models predict slight decreases and slight increase in D3 durations, but not by significant margins. The predictions for the serious D6 events do, however, consistently agree that drought durations will increase by $\sim 1.9$ months.

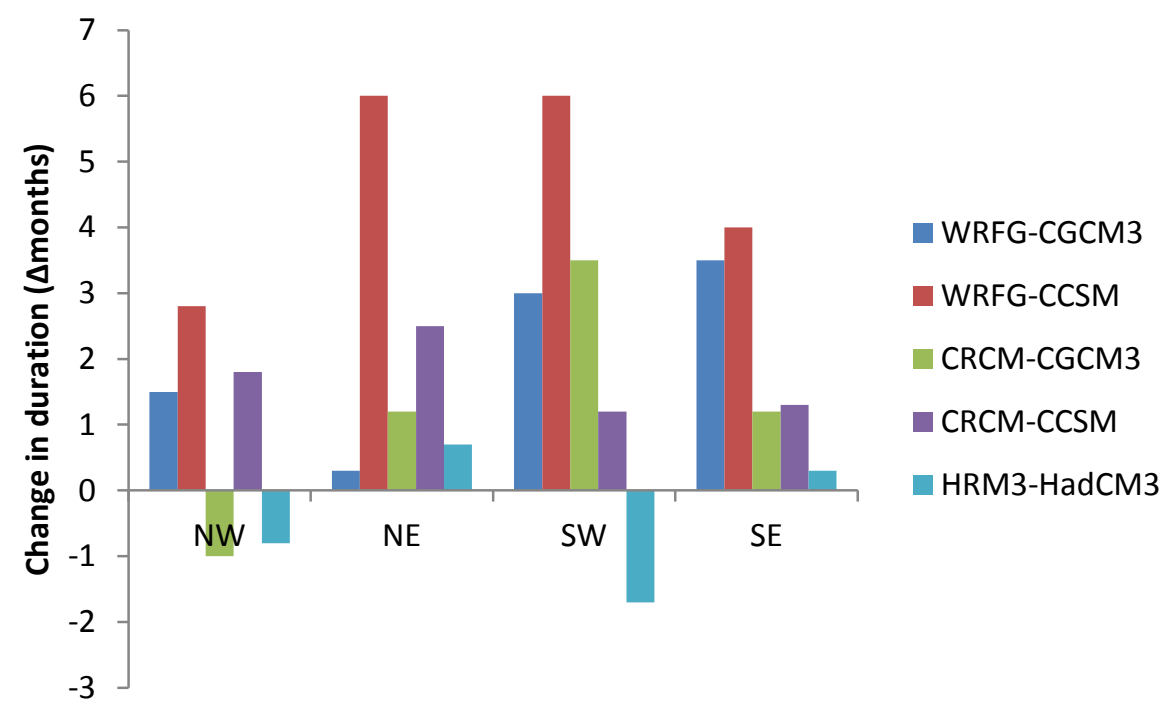

Figure 15: Change in the duration of serious events from 1971-1998 to 2041-2068. 
The final drought characteristic captured by the D3 and D6 statistic is drought intensity with respect to mean annual precipitation. For both the minor and serious drought events, the NARCCAP data predict an increase in drought intensity.

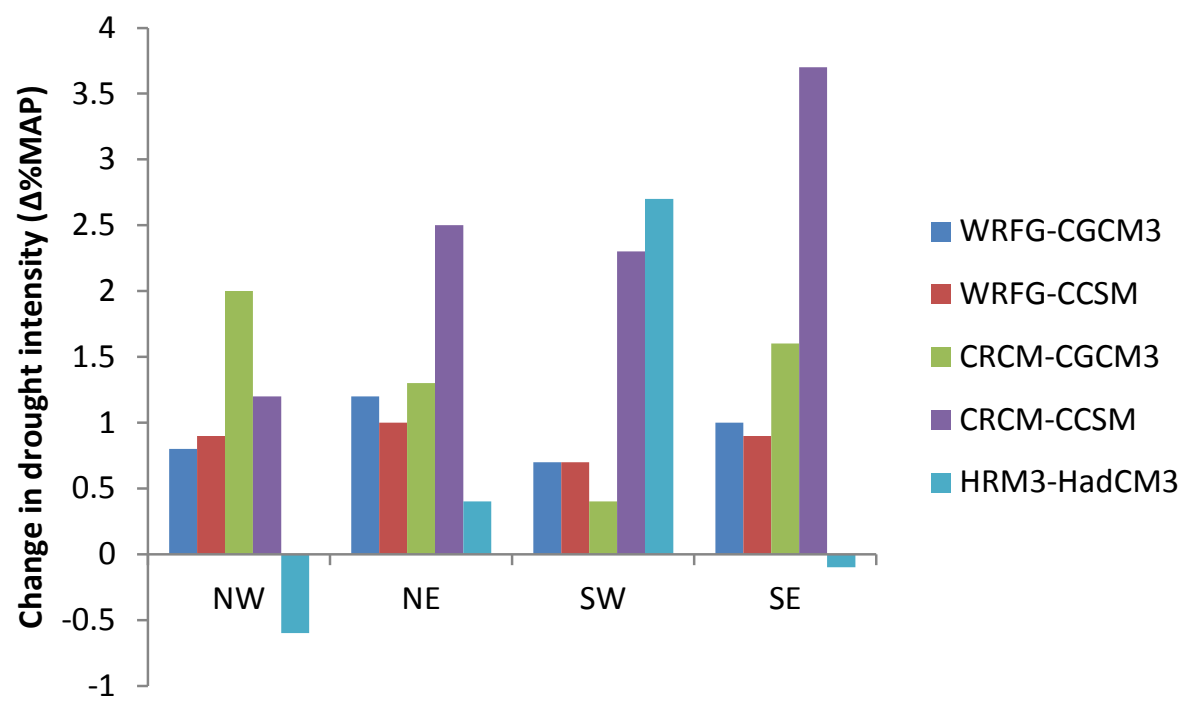

Figure 16: Change in the intensity of drought events from 1971-1998 to 2041-2068. 


\subsection{PRMS Modeling}

The final step in assessing the future hydrology of the Molalla-Pudding basin was through hydrologic modeling with the Precipitation-Runoff Modeling System. Evaluating the changes in runoff and soil moisture, in addition to the precipitation anomalies just described, will contribute to a multivariate understanding of water resources under future climate.

Before running the PRMS model with the predicted future datasets, the accuracy of the calibration was validated by comparing runoff results to observed streamflow data from the US Geological Survey. The primary statistics of interest were the correlation coefficient and the Nash-Sutcliffe value; the results of model validation are presented in table 5. Since the Molalla Pudding basin is primarily ungauged, there were only four observed data records that were used for validation. The correlation (0.83-0.91) and NS (0.69-0.80) statistics indicated that the PRMS model was well calibrated, so future runs were completed using the NARCCAP precipitation and temperature data.

Table 5: Statistics to verify the accuracy of the Molalla Pudding PRMS calibration.

\begin{tabular}{|l|l|c|c|c|}
\hline USGS Gage & River & Period & Correlation & $\begin{array}{c}\text { Nash- } \\
\text { Sutcliffe }\end{array}$ \\
\hline 14198500 & $\begin{array}{l}\text { Molalla River near } \\
\text { Wilhoit }\end{array}$ & $1971-1993$ & 0.83 & 0.69 \\
\hline 14200300 & Silver Creek at Silverton & $1971-1979$ & 0.91 & 0.75 \\
\hline 14201500 & Butte Creek at Monitor & $1971-1985$ & 0.91 & 0.80 \\
\hline 14200000 & Molalla River near Canby & $1971-1979$ & 0.90 & 0.80 \\
\hline
\end{tabular}

The PRMS model driven with NARCCAP precipitation and temperature data produced estimates of streamflow over the historical and future periods. Over the historical period, the NARCCAP modeled streamflow ranged 2350-2620 cfs, and over 
the future period, the NARCCAP modeled streamflow ranged 2160-2850 cfs. Generally the models predicted increased streamflow, due to increased precipitation. Additionally, over the historical period the NARCCAP modeled streamflow matched the decreasing trend of streamflow seen in the observe data. Predicted future streamflow, however, showed an increasing trend.

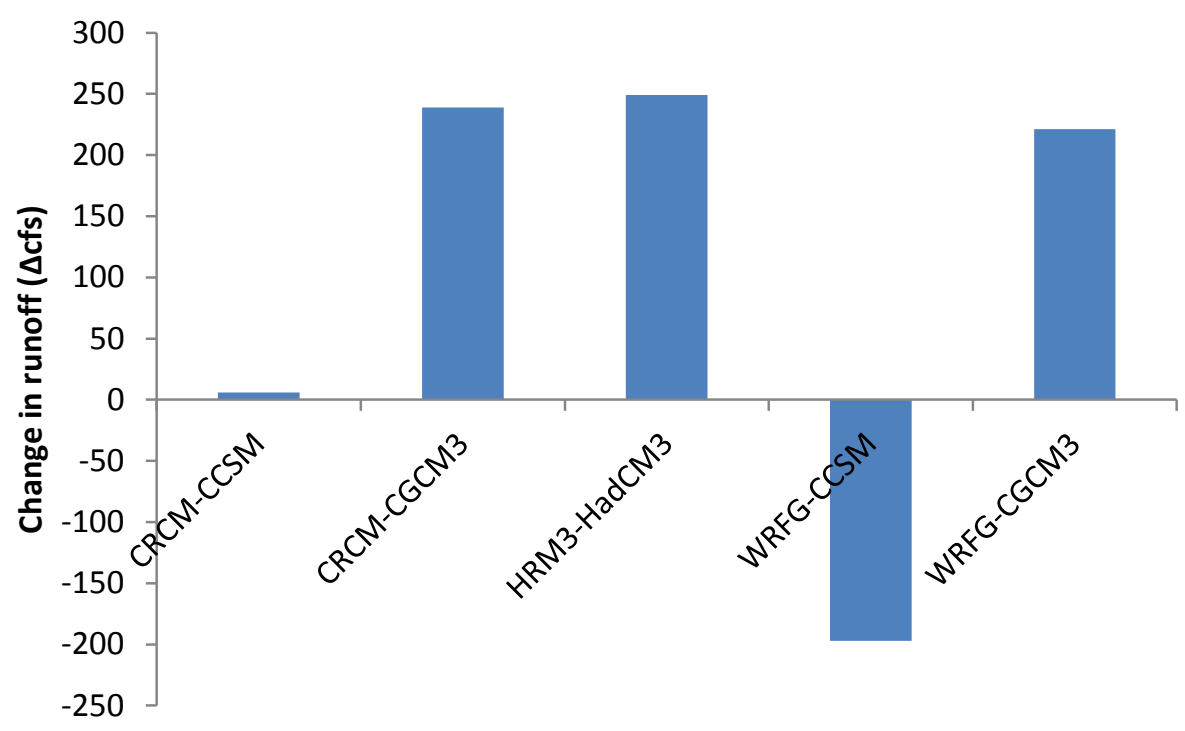

Figure 17: Change in total runoff from 1971-1998 to 2041-2068. 


\section{Seasonal Change in Runoff 2041-2068}

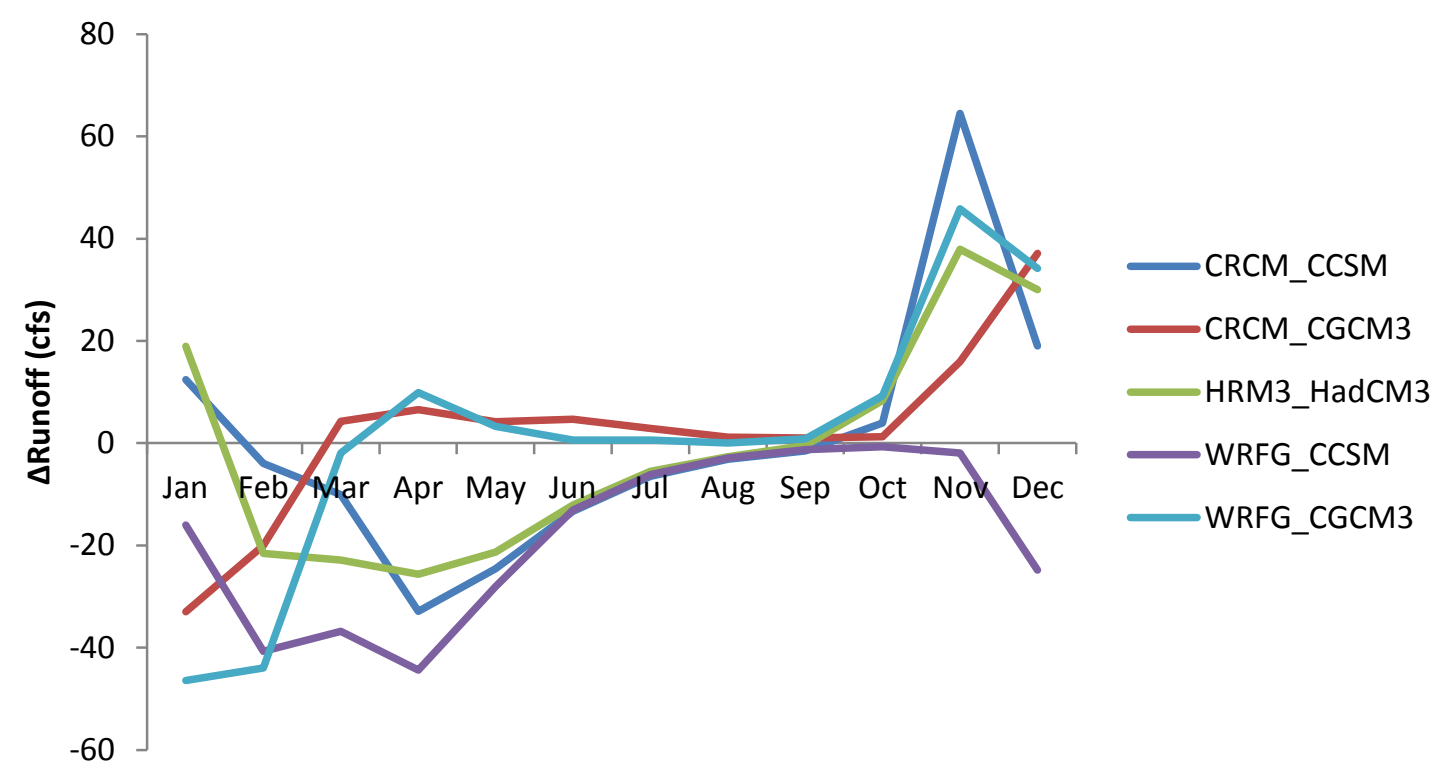

Figure 18: Changes in future seasonal runoff predicted by the five PRMS models driven by the CRCM-CCSM, CRCM-CGCM3, HRM3-HadCM3, WRFG-CCSM and WRFGCGCM3 NARCCAP datasets. 


\subsection{Water Vulnerability Index}

Using the demographic information from the 2000 US Census, the water demand information from the State of Oregon Water Resources Department and the output of the PRMS model runs driven by historical and future NARCCAP data, the WVIs were calculated for the twelve cities being evaluated. The WVIs were calculated for each model separately to provide five historical WVIs and five future WVIs for each city. A final cumulative WVI was calculated by averaging all NARCCAP driven PRMS outputs over both the historical and future periods. Figures 19 and 20 display the WVI scores for all cities in ascending order, so that the cities with the highest WVI are the most vulnerable.

The DDWV values between the cities were more variable than the SDWV values and ranged $14-53 \%$. Assessing the DDWV values first, the four most vulnerable cities of Gervais, Mount Angel, Hubbard and Woodburn, had the highest percentage of the population in poverty, the highest percentage of individuals employed in a waterdependent sector (agriculture), high water demands for irrigation and high population density. The four least vulnerable cities of Scotts Mills, Barlow, Aurora and Colton, on the other hand, tended to have unique combinations of variables that contributed to low vulnerability, however, the common thread was low agriculture economics. Scotts Mills generally had low vulnerability for all categories, and the lowest vulnerability with respect to habitat (as described by stream temperature). Barlow and Colton generally had low vulnerability in all categories, except population/population density and stream temperature. Finally, Aurora had high vulnerability due to the upstream agriculture demands and due to stream temperature, but low vulnerability for all other categories. 
The SDWV values between the cities were less variable, and generally ranged 20$42 \%$. The cities with the two greatest SDWV scores were Woodburn and Hubbard due to their high irrigation demands and lower runoff. The cities with the two lowest SDWV scores were Aurora and Barlow due to their high runoff, low irrigation demands and low vulnerability groundwater supply.

As can be seen in figures 19 and 20, the historical and future periods show much agreement in the ranking of vulnerable cities. The WVI tended to rank the small, low agriculture cities of Scotts Mills, Barlow, Aurora and Colton as being the least vulnerable. These cities have fewer upstream demands for water and are well equipped to handle social demands. The WVI tended to rank the furthest west cities of Woodburn, Hubbard, Gervais and Mount Angel as being the most vulnerable. These cities have great agricultural demands placed on water and are located at lower elevations generally receiving less precipitation and runoff. These cities do tend to be primarily groundwater dependent, however, the combination of low runoff and high demand for irrigation and agriculture make the region highly vulnerable. 


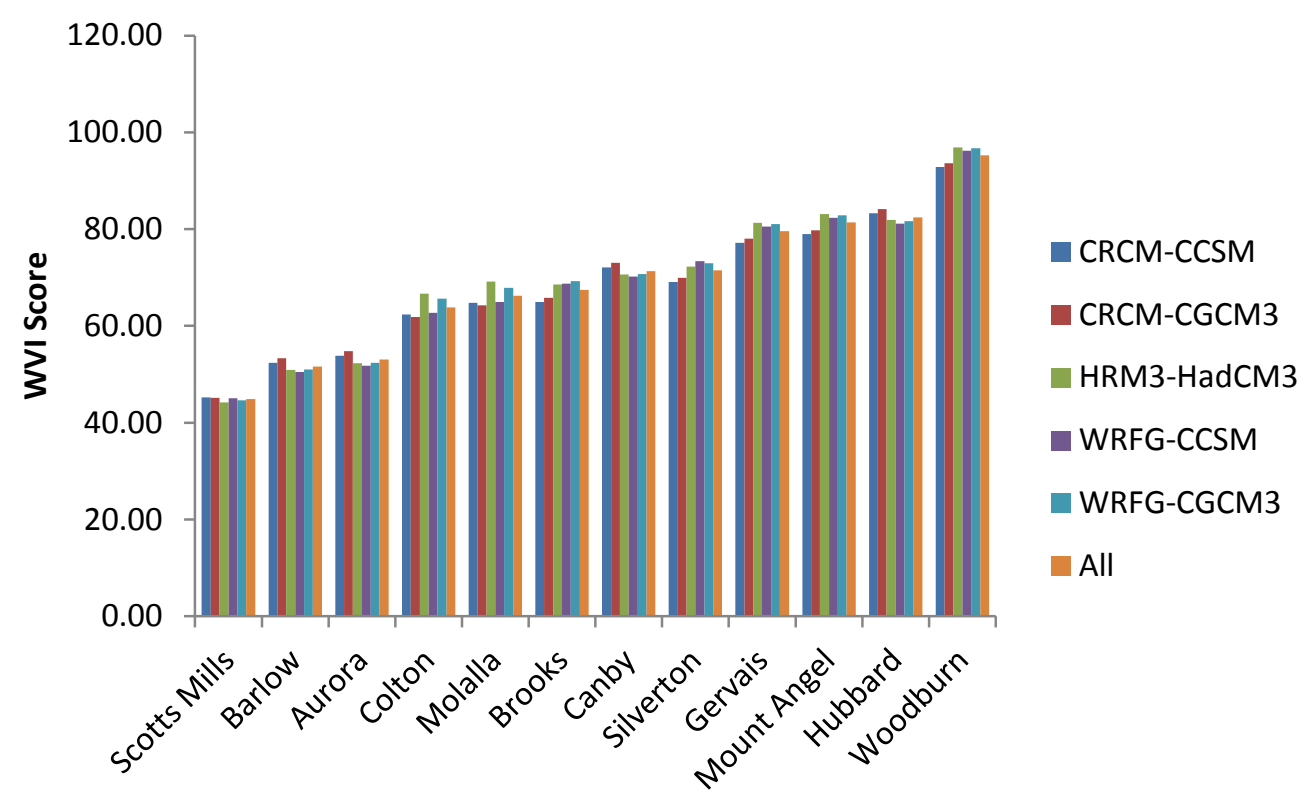

Figure 19: Historical period 1971-1998 WVI scores for Molalla Pudding basin cities. Cities on the left are least vulnerable and cities on the right are most vulnerable.

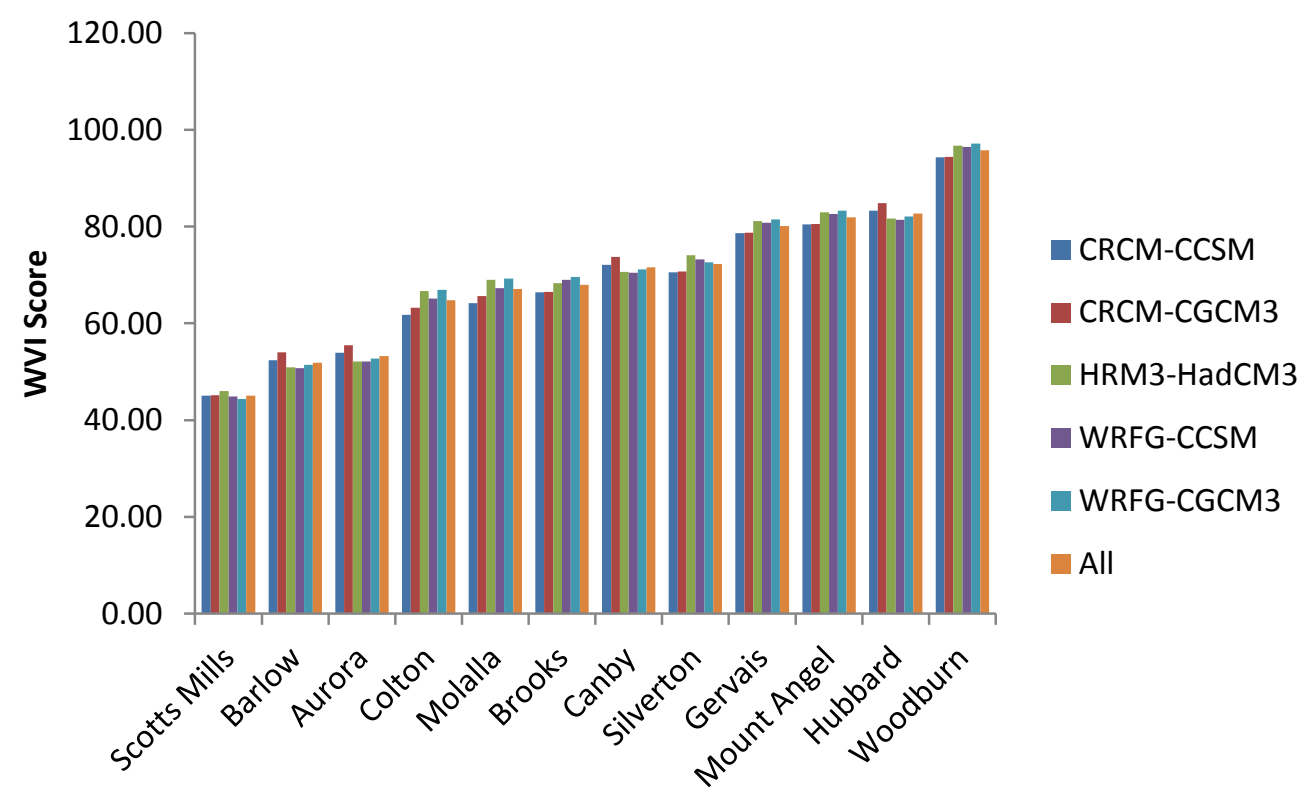

Figure 20: Future period 2041-2068 WVI scores for Molalla Pudding basin cities. Cities on the left are least vulnerable and cities on the right are most vulnerable. 


\subsection{Social Vulnerability Index with Water Components}

Using the SOVI variables outlined in the methods section, the drought indices and the components of water vulnerability used in the WVI, the SOVI + WC was calculated for the historical and future periods. The individual PRMS outputs for each of the NARCCAP datasets were all put into the table for principal components analysis and thus the SOVI + WC represents all RCMs.

Tables 6 and 7 outline the varimax rotated principal components determined for the historical and future periods. Both periods showed similar categorizations of principal components, with slight differences for the lower ranked components. Overall, the first three components described $\sim 55-60 \%$ of the variance of the dataset over both periods, inclusion of nine principal components for the historical period described $~ 97 \%$ of the variance and inclusion of ten principal components for the future period described $\sim 99 \%$ of the variance.

The variable loadings associated with the principal components, shown in tables 6 and 7 , indicate interesting relationships between water demand and social vulnerability. Component one indicates high positive loading from water variables associated with agriculture (demand, low precipitation in the western basin) and high positive loading from Spanish population/minority population social variables, implying a connection between Spanish laborers and agriculture. Component two indicates high positive loading from runoff and Asian population (generally considered less socially vulnerable) and high negative loading from percent of population in poverty and unemployment, indicating people with less wealth would be more inclined to live in regions with less available water. Component three, interestingly, had high positive loading from variables 
indicating female and elderly populations and from stream temperature and had high negative loading from agriculture employment. This could indicate that fewer women and elderly persons were found working in agriculture and that increased agriculture was found in regions with lower stream temperatures.

As can be seen in figure 21 , the historical and future periods show much agreement in the ranking of vulnerable cities. The SOVI + WC tended to rank the furthest upstream and furthest east cities of Colton, Molalla, Silverton and Aurora as being the least vulnerable as these regions had the greatest precipitation, low evaporation and fewer droughts. The SOVI + WC tended to rank the western cities of Mount Angel, Gervais, Woodburn and Hubbard as being the most vulnerable as these regions had less precipitation, less runoff and high evaporation. 
Table 6: Principal components and associated vulnerability dimensions for the Molalla Pudding basin over the historical period.

\begin{tabular}{|c|c|c|c|}
\hline $\mathbf{P C}$ & High Positive Loading & High Negative Loading & $\begin{array}{c}\% \\
\text { Variance } \\
\text { Explained } \\
\end{array}$ \\
\hline 1 & $\begin{array}{l}\text { Low Precipitation } \\
\text { Variability } \\
\text { Drought Length } \\
\text { Drought Intensity } \\
\text { Urbanization } \\
\text { Demand } \\
\text { Spanish Population } \\
\text { Minority Population }\end{array}$ & High Precipitation & 28 \\
\hline 2 & $\begin{array}{l}\text { Runoff } \\
\text { Asian Population }\end{array}$ & $\begin{array}{l}\text { Population in Poverty } \\
\text { Unemployment }\end{array}$ & 22 \\
\hline 3 & $\begin{array}{l}\text { Female Labor } \\
\text { Female Population } \\
\text { Population over } 65 \\
\text { Pop with Social Security } \\
\text { Stream Temperature }\end{array}$ & $\begin{array}{l}\text { People per Household } \\
\text { Agriculture Employment }\end{array}$ & 10 \\
\hline 4 & $\begin{array}{l}\text { Percent children } \\
\text { Indian Population } \\
\text { Immigrant Population } \\
\text { Female Head of Household }\end{array}$ & $\begin{array}{l}\text { Rural farm population } \\
\text { Median age }\end{array}$ & 8 \\
\hline 5 & $\begin{array}{l}\text { Renters } \\
\text { Nursing Home Residents } \\
\text { Housing density } \\
\text { Urban population }\end{array}$ & Mobile Home population & 8 \\
\hline 6 & $\begin{array}{l}\text { Transportation employment } \\
\text { Service industry employment }\end{array}$ & Labor employment & 7 \\
\hline 7 & $\begin{array}{l}\text { Wealth } \\
\text { Income } \\
\text { Housing value }\end{array}$ & Low education & 6 \\
\hline 8 & $\begin{array}{l}\text { Number drought events } \\
\text { GW resources }\end{array}$ & NA & 5 \\
\hline 9 & Irrigation & NA & 3 \\
\hline
\end{tabular}


Table 7: Principal components and associated vulnerability dimensions for the Molalla Pudding basin over the future period.

\begin{tabular}{|c|c|c|c|}
\hline PC & High Positive Loading & High Negative Loading & $\begin{array}{c}\% \\
\text { Variance } \\
\text { Explained } \\
\end{array}$ \\
\hline 1 & $\begin{array}{l}\text { Low Precipitation } \\
\text { Variability } \\
\text { Drought Length } \\
\text { Drought Intensity } \\
\text { Urbanization } \\
\text { Demand } \\
\text { Spanish Population } \\
\text { Minority Population }\end{array}$ & High Precipitation & 24 \\
\hline 2 & $\begin{array}{l}\text { Runoff } \\
\text { Asian Population }\end{array}$ & $\begin{array}{l}\text { Population in Poverty } \\
\text { Unemployment }\end{array}$ & 21 \\
\hline 3 & $\begin{array}{l}\text { Female Labor } \\
\text { Female Population } \\
\text { Population over } 65 \\
\text { Pop with Social Security } \\
\text { Median age } \\
\text { Stream Temperature }\end{array}$ & $\begin{array}{l}\text { People per Household } \\
\text { Agriculture Employment }\end{array}$ & 10 \\
\hline 4 & $\begin{array}{l}\text { Percent children } \\
\text { Indian Population } \\
\text { Immigrant Population } \\
\text { Female Head of Household }\end{array}$ & $\begin{array}{l}\text { Rural farm population } \\
\text { Median age }\end{array}$ & 8 \\
\hline 5 & $\begin{array}{l}\text { Renters } \\
\text { Nursing Home Residents } \\
\text { Housing density } \\
\text { Urban population }\end{array}$ & Mobile Home population & 8 \\
\hline 6 & Drought Intensity & GW Resources & 7 \\
\hline 7 & $\begin{array}{l}\text { Wealth } \\
\text { Income } \\
\text { Housing value }\end{array}$ & Low education & 7 \\
\hline 8 & $\begin{array}{l}\text { Transportation employment } \\
\text { Service industry employment }\end{array}$ & Labor employment & 6 \\
\hline 9 & $\begin{array}{l}\text { Number drought events } \\
\text { Irrigation }\end{array}$ & NA & 4 \\
\hline 10 & Storage variability & NA & 4 \\
\hline
\end{tabular}




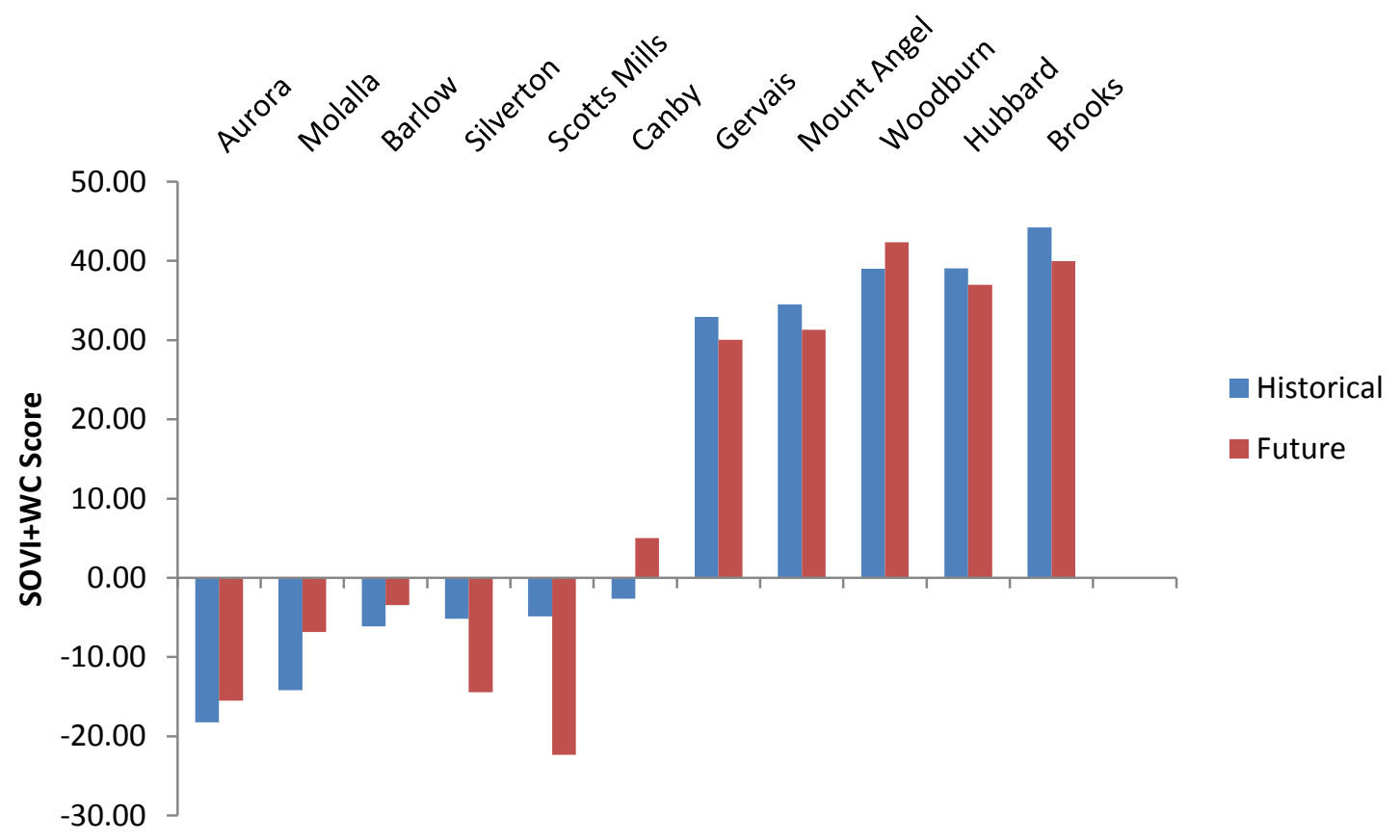

Figure 21: Historical and future SOVI + Water Component scores for Molalla Pudding basin cities. Cities on the left are least vulnerable and cities on the right are most vulnerable. 


\subsection{Comparison of Vulnerability Indices}

Once the two different approaches to calculating vulnerability indices were completed, the relative rankings of cities could be compared and discussed. Figures 22 and 23 compare the rankings of the twelve cities based on output of the vulnerability indices, and one can see that there is much agreement. The two methods consistently ranked the cities of Woodburn, Hubbard, Gervais and Mount Angel as the most vulnerable due to their position in the lower precipitation portion of the basin and due to the extensive irrigation and agriculture demands placed on the water supply. The two methods also consistently ranked Colton as the least vulnerable city due to its high rainfall and position upstream. The cities of Scotts Mills, Silverton, Molalla, Aurora and Barlow also were consistently ranked as having low vulnerability, while Brooks and Canby had mid-level vulnerability.

In terms of use and access to data, the two methods were similar in their data requirements. The WVI was generally easier to use because of the lower number of required input variables and straightforward calculation, however, there were several aspects of social vulnerability unaccounted for. The SOVI + WC had a greater data requirement and involved the use of a complicated calculation, that required user interpretation, however many aspects of vulnerability could be accounted for. Overall, the WVI was a good index for quick calculations, however, the SOVI + WC index could be very beneficial for evaluating large areas with great diversity and broad distributions of vulnerable groups. 


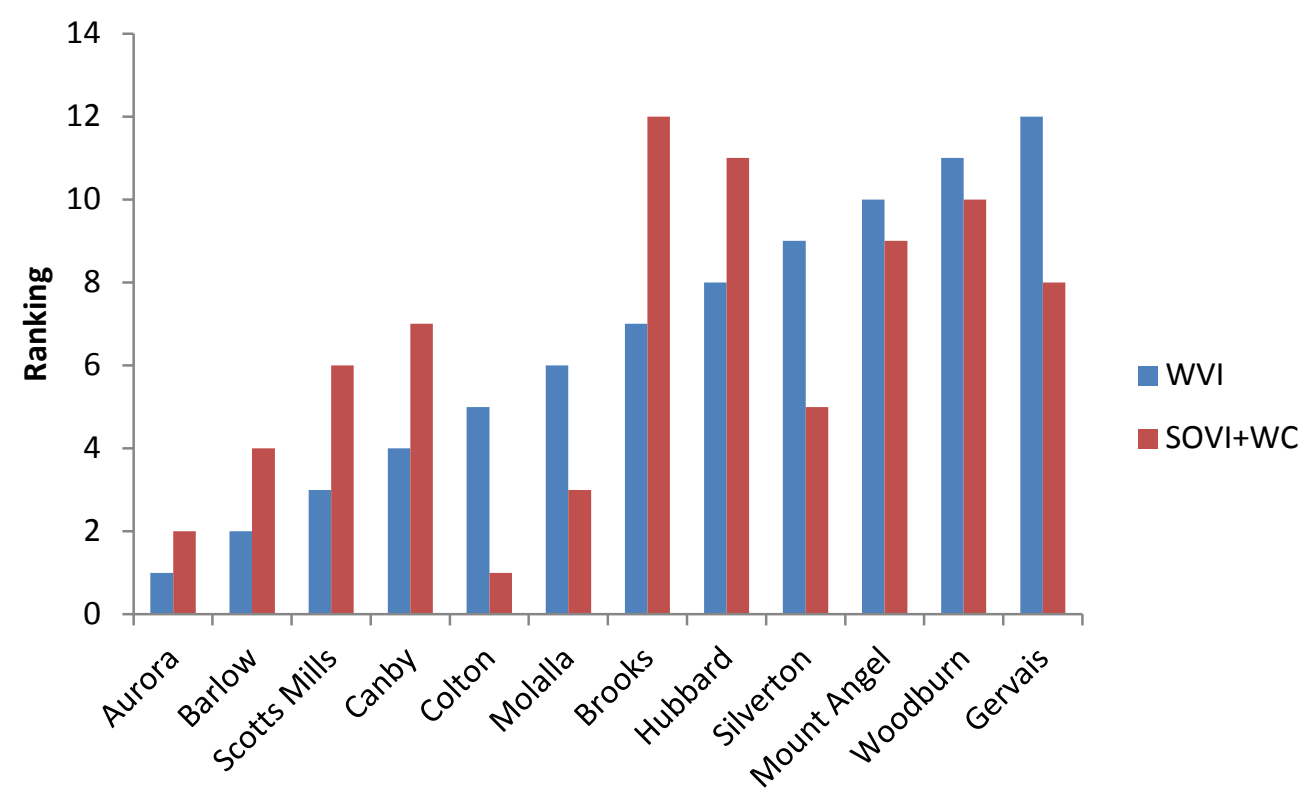

Figure 22: Comparison of WVI and SOVI + WC rankings for the historical period.

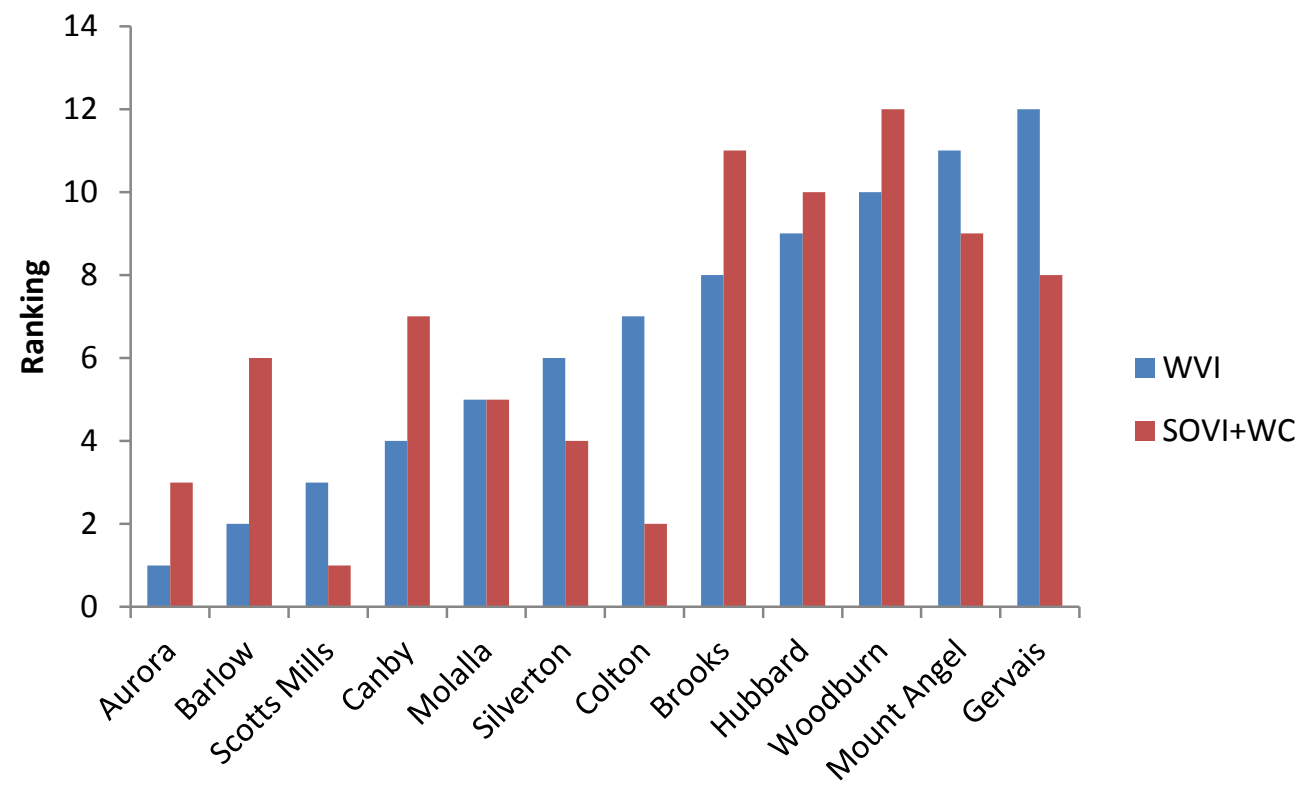

Figure 23: Comparison of WVI and SOVI + WC rankings for the future period. 


\section{Chapter 4 Discussion}

The vulnerability indices used in this research were useful tools for determining which cities in the Molalla Pudding basin relied on vulnerable water supplies. The indices while useful, however, are not perfect and will only reflect vulnerabilities represented by the input data. One of the deficiencies of the existing vulnerability indices is the lack of water quality data and the lack of environmental vulnerability, as most variables focus on human demand. In the Pacific Northwest, for example, human water shortages tend to be infrequent, however, instream flow and quality requirements for habitat are often not met. Additionally, the presence of dangerous constituents in waterways makes vulnerability from intake and recreation a real possibility. In developing indices that include water quality measures, the user should be very careful in determining which constituents should be considered and how those constituents should be weighted. As can be seen in figure 24, cities like Hubbard, Woodburn and Gervais, which were consistently ranked as most vulnerable, may not have the same water quality problems with respect to bacteria and hexavalent chromium. A city like Colton which was consistently ranked as having lowest vulnerability, however, was one of the few cities with a TMDL for hexavalent chromium, a dangerous carcinogen. This demonstrates importance of carefully selecting water quality constituents.

Additionally, some variables, like dams, may be beneficial to one group and detrimental to another. From a human water supply perspective, dams are quite useful, while from an anadromous fish perspective, dams make fish passage to breeding grounds impossible. Other variables that can be tricky to evaluate are extreme precipitation events and high runoff. A city like Aurora received a low vulnerability rating because its 
position at the confluence of the Mill and Pudding rivers ensures high runoff access. Aurora is also very susceptible to flooding events because of its position, and that vulnerability is not fully accounted for in the existing indices.

Another deficiency in the water vulnerability indices presented in this paper is the lack of predicted population growth for future index calculations. The 2000 Census and geographic data were not modified for expected changes in growth and land use, so predicted vulnerability could be affected by these areas. For example, a large city with high water demand could be ranked as having high vulnerability even if its future growth is quite small. While a small town with low historical demand could be more vulnerable in the future due to relatively high population growth and development. These concepts should be considered in further climate change vulnerability studies. 

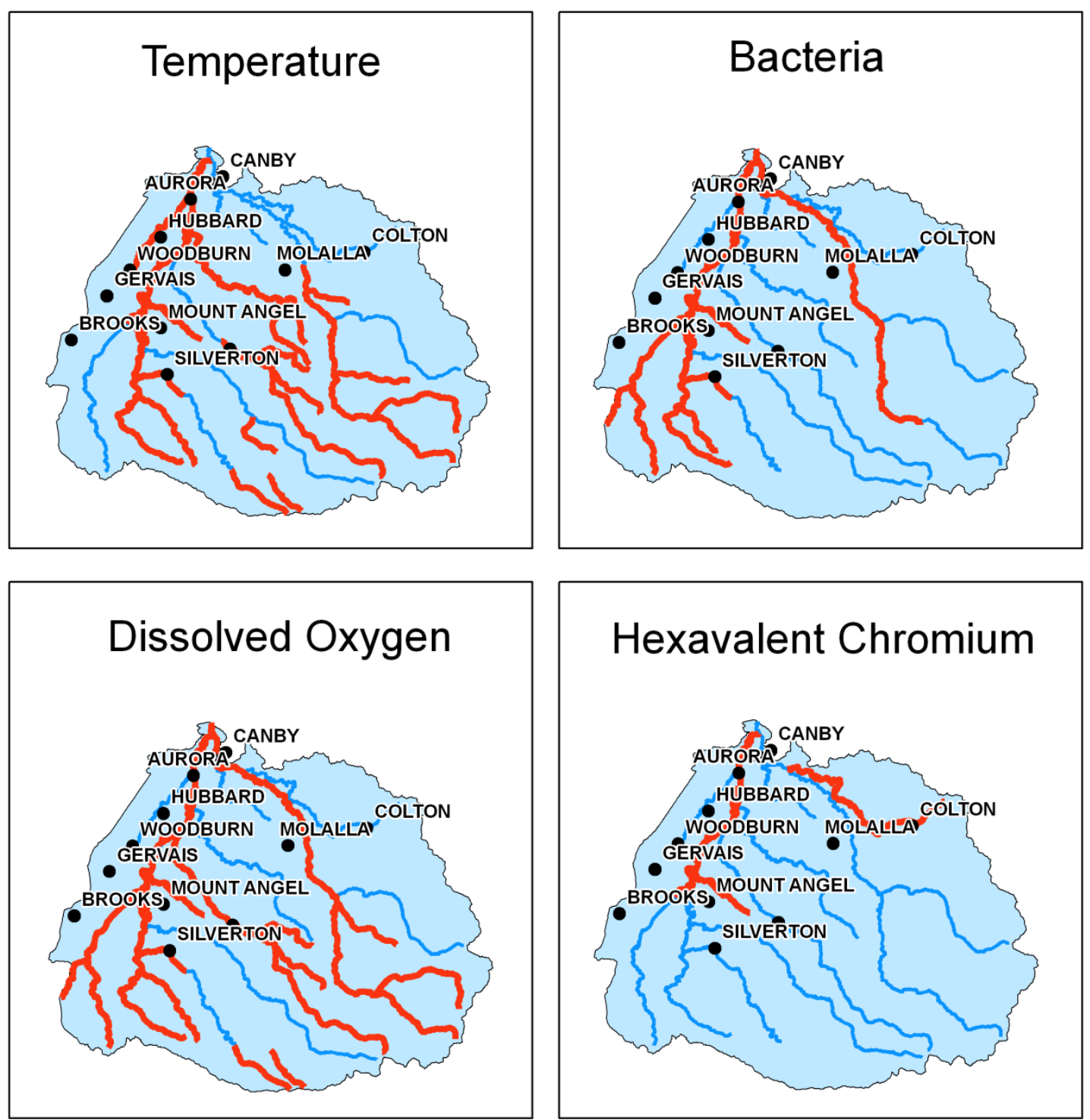

\section{Hexavalent Chromium}

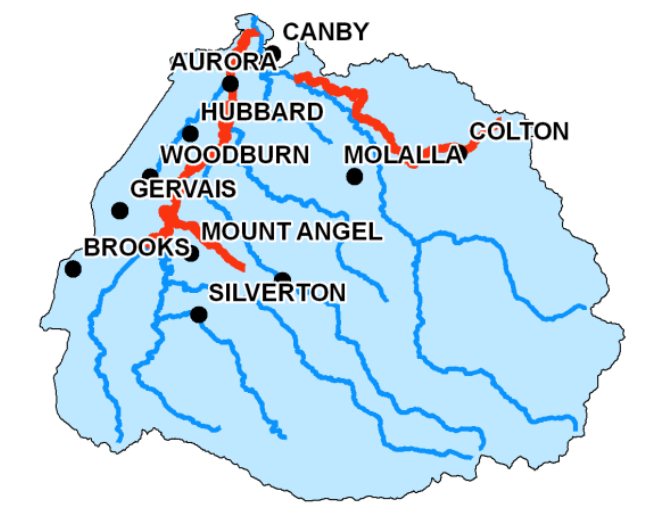

Figure 24: Stream reaches (red) with existing Total Maximum Daily Load (TMDL) requirements for various water quality and habitat vulnerability variables. 


\section{Chapter 5 Conclusion}

Overall, the predicted climate data shows increases in precipitation and temperature in the future period 2041-2068. These variables exhibit an increasing trend and precipitation increases are greater in the eastern portion of the basin where the Cascade mountain range is located. These increases tend to translate to an increase in basin runoff, but a small decrease in soil moisture. The seasonality of runoff is also predicted to change with decreased flows in the Winter/Spring months, little to no change of flow in the Summer months and increased flow in the Fall months. While the Molalla Pudding basin is not a snowmelt driven basin, the changes in seasonality could be due to increased temperatures removing a snow component. If more precipitation is falling as rain, then an increased Fall runoff would be expected.

The climate change data also predict differences in future droughts, as defined by precipitation anomaly indices. Minor drought occurrences are expected to decrease by 12 events per 30 year period, while serious drought occurrences are not expected to change. Duration of minor drought events are not expected to change, while serious drought events are predicted to increase by 1-2 months on average. Both minor and serious drought intensities (with respect to mean annual precipitation) are expected to increase but only by $1-8 \%$ on average.

The calculations of vulnerability indices provided a ranking of vulnerability by city in the Molalla Pudding basin that could be a useful management tool in water resources applications. Overall the two vulnerability measures had good agreement in the rankings and both tended to list the westernmost cities of Woodburn, Gervais, 
Hubbard and Mount Angel as being the most vulnerable to water scarcity. Since these cities compete with high irrigation and agriculture demands in a region receiving less precipitation than the eastern basin, management plans should account for alternative or supplemental water sources during times of extreme drought or low precipitation periods. 


\section{References}

Blenkinsop, S., Fowler, H.J., Changes in drought frequency, severity and duration for the British Isles projected by the PRUDENCE regional climate models, Journal of Hydrology, 342: 50-71.

Boix, D., Garcia-Berthou, E., Gascon, S., Benejam, L., Tornes, E., Sala, J., Benito, J., Munne, A., Sola, C., Sabater, S., 2010. Response of community structure to sustained drought in Mediterranean rivers, Journal of Hydrology, 383: 135-146.

Chang, H., Jung, I.W., 2010. Spatial and temporal changes in runoff caused by climate change in a complex large river basin in Oregon, Journal of Hydrology, 388: 186-207.

Dunning, C.M., Durden, S., 2011. Social Vulnerability Analysis Methods for Corps Planning. US Army Corps of Engineers Institute of Water Research 2011-R-07.

Fowler, H.J., Kilsby, C.G., 2002. A weather-type approach to analyzing water resource drought in the Yorkshire region from 1881-1998, Journal of Hydrology, 262: 177-192.

Fowler, H.J., Kilsby, C.G., 2004. Future increases in UK water resource drought projected by a regional climate model, Hydrology: Science \& Practice for the $21^{\text {st }}$ Century, 1: 15:21.

Fujihara, Y., Tanaka, K., Watanabe, T., Nagano, T., Kojiri, T., 2008. Assessing the impacts of climate change on the water resources of the Seyhan River Basin in Turkey: Use of dynamically downscaled data for hydrologic simulations, Journal of Hydrology, 353: $33-48$.

Haykin, S., 1999. Neural Networks: A Comprehensive Foundation, $2^{\text {nd }}$ Edition, PrenticeHall Inc., Upper Saddle River, NJ.

Jiang, Y., 2009. China's water scarcity, Journal of Environmental Management, 90: 3185-3196.

Johnson, F., Sharma, A., 2011. Accounting for Interannual Variability: A Comparison of Options for Water Resources Climate Change Impact Assessments. Water Resources Research, 47. doi: 10.1029/2010WR009272.

Jung, I.W., Chang, H., 2011a. Assessment of future runoff trends under multiple climate change scenarios in the Willamette River Basin, Oregon, USA, Hydrological Processes, 25: $258-277$.

Jung, I.W., Chang, H., 2011b. Climate change impacts on spatial patterns in drought risk in the Willamette River Basin, Oregon, USA, Theor. Appl. Climatol., DOI 10.1007/s00704-011-0531-8 
Kaiser, H.F., 1958. The varimax criterion for analytic rotation in factor analysis. Psychometrika, 23(3), 187-200.

Kaiser, H.F., 1960. The application of electronic computers to factor analysis, Educational and Psychological Measurement, 20, 141-151.

Laenen, A., Risley, J. C., 1997. Precipitation-Runoff and Streamflow Routing Models for the Willamette River Basin, Oregon. US Geological Survey Water-Resources Investigations Report 95-4284.

Lee, K., K., Risley, J. C., 2002. Estimates of Ground-Water Recharge, Base Flow, and Stream Reach Gains and Losses in the Willamette River Basin, Oregon. US Geological Survey Water-Resources Investigations Report 01-4215.

Markstrom, S.L., Niswonger, R.G., Regan, R.S., Prudic, D.E., Barlow, P.M., 2008. GSFLOW - Coupled Ground-Water and Surface-Water Flow Model Based on the Integration of the Precipitation-Runoff Modeling System (PRMS) and the Modular Ground-Water Flow Model (MODFLOW-2005). "Modeling Techniques Section D, Ground-Water/Surface-Water", Chapter 1, USGS.

Moradkhani, H., Baird, R.G., Wherry, S., 2010. Assessment of Climate Change Impact on Floodplain and Hydrologic Ecotones. Journal of Hydrology, 395: 264-278. doi:10.1016/j.jhydrol.2010.10.038.

Najafi, M., Moradkhani, H., Wherry, S., (2011). Statistical Downscaling of Precipitation using Machine Learning with Optimal Predictor Selection. Journal of Hydrologic Engineering, doi:10.1061/(ASCE)HE.1943-5584.0000355, in press.

Ohlsson, L., 2000. Water Conflicts and Social Resource Scarcity, Phys. Chem. Earth (B), 25(3): 213-220.

Oladipo, E.O., 1985. A comparative performance analysis of three meteorological drought indices, Journal of Climatology, 5(6), 655-664.

Phillips, I.D., McGregor, G.R., 1998. The utility of a drought index for assessing the drought hazard in Devon and Cornwall, South West England, Meteorol. Appl., 5: 359372.

Salathe, E.P., Mote, P.W., Wiley, M.W., 2007. Review of Scenario Selection and Downscaling Methods for the Assessment of Climate Change Impacts on Hydrology in the United States Pacific Northwest. International Journal of Climatology, 27: 16111621. doi: 10.1002/joc.1540.

Sullivan, C., 2002. Calculating a Water Poverty Index, World Development, 30(7): 11951210. 
Sullivan, C.A., 2011. Quantifying water vulnerability: a multi-dimensional approach, Stoch. Environ Res Risk Assess, 25: 627-640.

Vidal, J.P., Wade, S., 2009. A multimodel assessment of future climatological droughts in the United Kingdom, International Journal of Climatology, 29: 2056-2071.

Wilby, R.L., Wigley, T.M.L., 1997. Downscaling General Circulation Model Output: A Review of Methods and Limitations. Progress in Physical Geography, 21(4): 530-548. doi: 10.1177/030913339702100403.

Wilby, R.L., Charles, S.P., Zorita, E., Timbal, B., Whetton, P., Mearns, L.O., 2004. Guidelines for Use of Climate Scenarios Developed from Statistical Downscaling Methods. 27 pages, available from, http://www.ipcc-data.org/

Williams, K.F., Bloom, J., 2008. Molalla Pudding Subbasin Total Maximum Daily Load and Water Quality Management Plan, State of Oregon, Department of Environmental Quality.

Wood, A.W., Leung, L.R., Sridhar, V., Lettenmaier, D.P., 2004. Hydrologic Implications of Dynamical and Statistical Approaches to Downscaling Climate Model Outputs. Climatic Change, 62: 189-216. 